\title{
A user-oriented methodology for DInSAR time series analysis and interpretation: landslides and subsidence case studies
}

\author{
Notti Davide ${ }^{1,4}$, Fabiana Calò $^{2}$, Francesca Cigna ${ }^{3}$, Michele Manunta ${ }^{2}$, Gerardo Herrera ${ }^{4,7,8}$, \\ MatTeo Berti ${ }^{5}$, Claudia Meisina ${ }^{1}$, DeOdato TAPETE ${ }^{6}$, Francesco ZuCCA $^{1}$
}

1 - Earth and Environmental Science Department - University of Pavia, Via Ferrata, 127100 Pavia, Italy E-MAIL: davide.notti@unipv.it

2 - CNR - IREA, via Diocleziano 328, 80124 Napoli, Italy, calo.f@irea.cnr.it; manunta.m@irea.cnr.it

3 - British Geological Survey (BGS) - Natural Environment Research Council (NERC), Nicker Hill, Keyworth, NG12 5GG Nottinghamshire, United Kingdom - fcigna@bgs.ac.uk

4 - Geohazards InSAR laboratory and Modeling group (InSARlab), Geoscience research department, Geological Survey of Spain (IGME), Alenza 1, E-28003 Madrid, Spain-g.herrera@igme.es

5 - Dipartimento di Scienze Biologiche, Geologiche e Ambientali - Università di Bologna, Via Zamboni 67 - 40126 Bologna, Italy-matteo.berti@unibo.it

6 - Department of Geography - Institute of Hazard, Risk and Resilience (IHRR), Durham University, Durham, UK deodato.tapete@durham.ac.uk

7- Unidad Asociada de investigación IGME-UA de movimientos del terreno mediante interferometría radar (UNIRAD), Universidad de Alicante, P.O. Box 99, 03080 Alicante, Spain

8- Earth Observation and Geohazards Expert Group (EOEG), EuroGeoSurveys, the Geological Surveys of Europe, 36 38, Rue Joseph II, 1000 Brussels, Belgium

\begin{abstract}
Recent advances in multi-temporal Differential Synthetic Aperture Radar (SAR) Interferometry (DInSAR) have greatly improved our capability to monitor geological processes. Ground motion studies using DInSAR require both the availability of good quality input data and rigorous approaches to exploit the retrieved Time Series (TS) at their full potential. In this work we present a methodology for DInSAR TS analysis, with particular focus on landslides and subsidence phenomena. The proposed methodology consists of three main steps: (1) pre-processing, i.e., assessment of a SAR Dataset Quality Index (SDQI), (2) post-processing, i.e., application of empirical/stochastic methods to improve the TS quality, and (3) trend analysis, i.e., comparative implementation of methodologies for automatic TS analysis. Tests were carried out on TS datasets retrieved from processing of SAR imagery acquired by different radar sensors (i.e., ERS-1/2 SAR, RADARSAT-1, ENVISAT ASAR, ALOS PALSAR, TerraSAR-X, COSMO-SkyMed) using advanced DInSAR techniques (i.e., SqueeSAR ${ }^{\mathrm{TM}}$, PSInSAR ${ }^{\mathrm{TM}}$, SPN and SBAS). The obtained values of SDQI are discussed against the technical parameters of each data stack (e.g., radar band, number of SAR scenes, temporal coverage, revisiting time), the retrieved coverage of the DInSAR results, and the constraints related to the characterization of the investigated geological processes. Empirical and stochastic approaches were used to demonstrate how the quality of the TS can be improved after the SAR processing, and examples are discussed to mitigate phase unwrapping errors, and remove regional trends, noise and anomalies. Performance assessment of recently developed methods of trend analysis (i.e., PS-Time, Deviation Index and velocity TS) was conducted on two selected study areas in Northern Italy affected by land subsidence and landslides. Results show that the automatic detection of motion trends enhances the interpretation of DInSAR data, since it provides an objective picture of the deformation behaviour recorded through TS and therefore contributes to the understanding of the on-going geological processes.
\end{abstract}

Keywords: Persistent Scatterers; Small BAseline Subset; SAR Interferometry; Time series analysis; Quality assessment; Subsidence; Landslides 


\section{Introduction}

The spatial and temporal monitoring of geological processes, such as subsidence, swelling/shrinkage of soils, or landslides, is crucial to understand their mechanisms, and therefore activate procedures of early warning and deploy suitable risk mitigation measures. In this respect, among the remote sensing technologies used for landslide hazard assessment (METTERNICH et al., 2005), space-borne Synthetic Aperture Radar (SAR) provides data from low to very high spatial resolution (smaller than one metre), day and night and all weather condition images with archives that, dependently on the space mission, can offer a high degree of coverage over Earth's surface. These unique imaging capabilities, thanks to recent advances in sensor technology and processing algorithms, boosted the use of SAR data for a wide range of geosciences and environmental applications. Among these, mapping and monitoring of natural hazards have greatly benefited in the last decade from the development of advanced multi-temporal Differential SAR Interferometry (DInSAR) techniques (e.g. PSInSAR ${ }^{\mathrm{TM}}$ by FERRETTI et al., 2001; SqueeSAR ${ }^{\mathrm{TM}}$ by FERRETTI et al., 2011 ; SPN by ARNAUD et al., 2003, SBAS by BERARDINO et al., 2002; CPT by BLANCO-SANCHEZ et al., 2008; MT-UnSAR by HoOPER, A. 2008, ISBAS by SOWTER et al., 2013; PSIG - Cousin PSs (CPSs) by DEVANTHÉRY et al., 2014). In particular, such Persistent Scatterer Interferometry (PSI) techniques were used for updating landslide inventories (e.g. COlesAnti AND WaSOWSKy, 2006; FARINA et al., 2006; MEISINA et al., 2008; CHEN et al., 2010; BIANCHINI et al., 2012; BoveGNA et al., 2012), as well as for detecting and mapping land subsidence (e.g. SouSA et al., 2010; TOMAS et al.2010, RASPINI et al., 2014; TEATINI et al., 2012).

So far, most deformation studies using DInSAR data were focused on the spatial analysis of ground movements using mainly the average rates of the displacements. Only in recent years, thanks to the improvement in processing techniques and the possibility to infer non-linear ground motions, it was also possible to take advantage of the capability of DInSAR techniques in describing the long-term evolution of natural processes (CALÒ et al., 2014). Furthermore, novel works were conducted in order to identify different trends in Time Series (TS) and to detect different phases of temporal evolution of a natural process: acceleration and deceleration, seasonality, sudden change in motion, trend inversion (MilONE AND SCEPI, 2011; CignA et al., 2012; BERTI et al., 2013).

Aim of this work is to extract the best out of the information contained in DInSAR data, in order to properly characterize the temporal evolution of ground displacements and improve the interpretation of geological processes. For the purpose, we propose a methodology for the analysis, and improvement, of TS produced by PSI processing techniques, with particular focus on landslides and subsidence phenomena. Our procedure, addressed to DInSAR users interested to fully exploit the potential of TS without working on the development of DInSAR processing chains, is composed by three main steps (see flowchart in Figure 1):

1. Pre-processing: evaluation of a SAR Dataset Quality Index (SDQI) that describes the expected quality of DInSAR products prior to the SAR image processing.

2. Post-processing: application of empirical/stochastic methods to improve the quality of already processed TS data.

3. Trend analysis: application and comparison of different approaches of TS trend analysis.

We applied this methodology to SAR data collected by different SAR sensors over different test areas, and processed with different DInSAR techniques as summarised in Table 1. We purposely selected these heterogeneous datasets to prove the effectiveness of the methodology in a wide range of application contexts. 


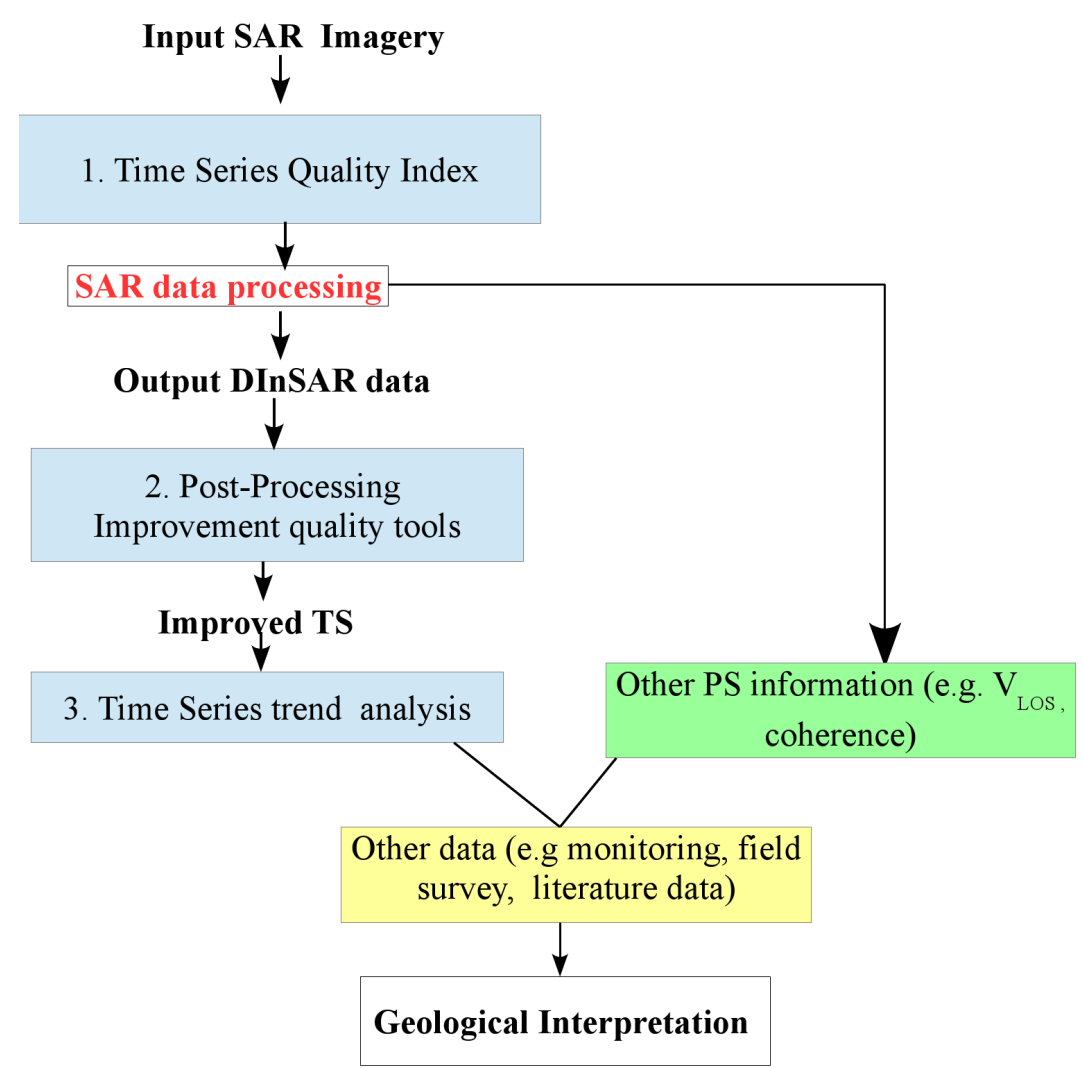

[Figure 1 Conceptual flow-chart of DInSAR time series analysis.]

\begin{tabular}{|c|c|c|c|c|c|c|c|c|}
\hline ID & Satellite & Band & Study area & $\begin{array}{c}\text { Area } \\
\mathbf{K m}^{2}\end{array}$ & $\begin{array}{c}\text { Type of } \\
\text { Processing }\end{array}$ & $\begin{array}{l}\text { Temporal } \\
\text { SPAN }\end{array}$ & $\begin{array}{c}\mathrm{N}^{\circ} \text { Of } \\
\text { Images }\end{array}$ & $\begin{array}{c}\text { Revisiting } \\
\text { Time (day) }\end{array}$ \\
\hline 1 & ERS-1/2 & $\mathrm{C}$ & $\begin{array}{c}\text { NW Italy } \\
\text { (5 datasets) }\end{array}$ & $>5^{\prime} 000$ & PSInSAR $^{\mathrm{TM}}$ & $1995-2001$ & $60 / 80$ & 35 \\
\hline 2 & $\begin{array}{l}\text { RADARSAT- } \\
1\end{array}$ & $\mathrm{C}$ & $\begin{array}{l}\text { NW Italy } \\
\text { (5 datasets) }\end{array}$ & $>5^{\prime} 000$ & SqueeSAR $^{\mathrm{TM}}$ & $2003-2010$ & $80 / 100$ & 24 \\
\hline 3 & ERS-1/2 & $\mathrm{C}$ & $\begin{array}{l}\text { Valle de Tena, } \\
\text { Spain }\end{array}$ & 33 & SPN & $1995-2001$ & 29 & 35 \\
\hline 4 & $\begin{array}{l}\text { ENVISAT } \\
\text { ASAR }\end{array}$ & $\mathrm{C}$ & $\begin{array}{l}\text { Valle de Tena, } \\
\text { Spain }\end{array}$ & 33 & SPN & $2003-2007$ & 37 & 35 \\
\hline 5 & $\begin{array}{l}\text { ALOS } \\
\text { PALSAR }\end{array}$ & $\mathrm{L}$ & $\begin{array}{l}\text { Valle de Tena, } \\
\text { Spain }\end{array}$ & 33 & SPN & $2006-2010$ & 12 & 46 \\
\hline 6 & TerraSAR-X & $\mathrm{X}$ & $\begin{array}{l}\text { Valle de Tena, } \\
\text { Spain }\end{array}$ & 33 & SPN & $\begin{array}{c}05 / 2008- \\
10 / 2008\end{array}$ & 11 & 11 \\
\hline 7 & $\begin{array}{l}\text { ERS-1/2, } \\
\text { ENVISAT }\end{array}$ & $\mathrm{C}$ & $\begin{array}{l}\text { Umbria, Central } \\
\text { Italy }\end{array}$ & 1200 & SBAS & $1992-2010$ & $91 / 37$ & 35 \\
\hline 8 & $\begin{array}{l}\text { COSMO- } \\
\text { SkyMed }\end{array}$ & $X$ & $\begin{array}{l}\text { Umbria, Central } \\
\text { Italy }\end{array}$ & 300 & SBAS & $\begin{array}{c}12 / 2009- \\
02 / 2012\end{array}$ & 39 & $4 / 16$ \\
\hline 9 & TerraSAR-X & $\mathrm{X}$ & $\begin{array}{c}\text { Umbria, Central } \\
\text { Italy }\end{array}$ & 216 & SBAS & $\begin{array}{l}07 / 2011- \\
01 / 2013 \\
\end{array}$ & 38 & 11 \\
\hline 10 & ENVISAT & $\mathrm{C}$ & $\begin{array}{c}\text { Daunia Apennines, } \\
\text { Southern Italy }\end{array}$ & 2200 & SBAS & $2003-2010$ & 37 & 35 \\
\hline 11 & TerraSAR-X & $\mathrm{X}$ & $\begin{array}{l}\text { Daunia Apennines, } \\
\text { Southern Italy }\end{array}$ & 1500 & SBAS & $\begin{array}{l}01 / 2010- \\
07 / 2012\end{array}$ & 24 & 11 \\
\hline
\end{tabular}

Table 1: Summary of DInSAR datasets used in this work 


\section{Pre-processing: SAR Dataset Quality Index (SDQI)}

\subsection{SDQI: input parameters and evaluation}

Products of advanced DInSAR techniques, i.e., mean deformation velocity maps and associated TS, can be effectively exploited for hazard and risk assessment, providing valuable information on the spatial and temporal evolution of deformation phenomena such us landslides and ground subsidence. This information can be complemented with ground-based monitoring data (e.g. inclinometers, extensometers, piezometers, and GPS) to deeply understand the longterm kinematical behaviour of geological phenomena, and to investigate the possible triggering factors of the detected ground motion. In this context, it can be very useful for end-users, such as surveyors, geologists, geoscientists, or land use planners, to assess the suitability of deformation TS for this kind of analysis.

To this purpose, we propose an innovative SAR Dataset Quality Index that provides a quantitative assessment of the impact that "decorrelation" phenomena, size of the dataset, and sensor wavelength exert on the performance of the multi-temporal DInSAR processing and the generation of ground motion TS. This index refers to the capability of the available SAR datasets to be effectively used to generate deformation velocity maps and associated TS, with a density of measure points suitable to carry out a comprehensive investigation of the study area.

SDQI can be easily implemented by users not necessarily expert in SAR processing, to assess the expected quality of the DInSAR results against the coverage or number of detectable measurement points.

Furthermore, when several SAR datasets are available for the same study area, the SDQI can be used to effectively select the most suitable dataset for the analysis of the investigated deformation phenomenon. In this way, the SDQI supports the design of the DInSAR monitoring activities.

The SDQI is calculated as weighted average of five indexes that account for the main parameters impacting on the number of coherent points detectable through a DInSAR processing:

$$
\mathrm{SDQI}=\frac{\left(N{ }^{*} w_{N I}+I^{*} w_{I I}+M I B I{ }^{*} w_{M I B I}+M S B I * w_{M S B I}+S R I^{*} w_{S R I}\right)}{w_{N I}+w_{I I}+w_{M I B I}+w_{M B B I}+w_{S R I}}
$$

Where:

- NI (Number of images Index) is associated to the number of acquisitions belonging to the selected SAR dataset;

- $\quad T I$ (Time Index) refers to the length of the whole time period spanned by the SAR dataset;

- $\quad M T B I$ (Mean Temporal Baseline Index) is associated to the average time interval between consecutive scenes;

- $\quad$ MSBI (Mean Spatial Baseline Index) refers to the average spatial baseline of the interferometric pairs;

- SRI (Spatial Resolution Index) is associated to the ground range resolution of the SAR scenes;

- $\quad$ and $\mathrm{w}_{N I}, w_{T I}, w_{M T B I}, w_{M S B I}, w_{S R I}$ are the respective weights.

Each index, below described in detail, is dimensionless, ranges between 0 and 1 and is properly weighted according to the values reported in Table 2. These weights are defined based on our experience related to analyses of phenomena with maximum displacements of the order of few centimetres per year. However, in case of geological processes characterized by high deformation rates (i.e., exceeding 5 centimetres per year), the weights can be easily adapted, in 
order to make the proposed methodology flexible with respect to the investigated processes, without modifying the calculation of the single indexes. In such a case, the MTBI weight should be properly increased to 3 or 4 , in order to make more significant the role of the temporal baseline with respect to other parameters. At the same time if we are not interested in the long-term behaviour of the deformation process, e.g., when we a priori know it is characterized by quasi-linear deformation trend, we can opportunely decrease the weight of Time Index. Moreover, if not all the parameters can be estimated, the SDQI assessment can be performed by setting equal to zero the weights corresponding to the unavailable parameters. For instance the Mean Baseline Spatial Index is not always accessible before processing the SAR dataset; therefore, in such a case, the SDQI could be based on 4 parameters and its reliability will not be affected.

The estimated SDQI value can be converted in a qualitative evaluation (see Table 3), via the identification of the following SDQI classes: Very Low (if SDQI $\leq 0.25$ ), Low (if $0.25<\mathrm{SDQI} \leq 0.45$ ), Medium (if $0.45<\mathrm{SDQI} \leq 0.65$ ), High (if $0.65<\mathrm{SDQI} \leq 0.75$ ), and Very High (if SDQI $>0.75$ )

\begin{tabular}{llc}
\hline Parameters & Weight & Weight Value \\
\hline $\begin{array}{l}\text { Number of images (NI) } \\
\text { (MTBI) }\end{array}$ & WNI & 2 \\
\hline Time Index (TI) & WMTBI & 2 \\
\hline $\begin{array}{l}\text { Mean Spatial Baseline Index } \\
\text { (MSBI) }\end{array}$ & WTI & 1 \\
\hline Spatial Resolution Index (SRI) & WSRI & 1 \\
\hline
\end{tabular}

Table 2: Weights assigned to each parameter of SAR Dataset Quality Index (SDQI)

\begin{tabular}{ccc}
\hline Value & SDQI & Condition \\
\hline Very Low & $\leq 0.25$ & Low confidence in TS and $\mathrm{V}_{\mathrm{LOS}}$ \\
\hline Low & $0.25-0.45$ & Use of average $\mathrm{V}_{\mathrm{LOS}}$ only \\
\hline Medium & $0.45-0.65$ & TS are likely to be noisy \\
\hline High & $0.65-0.75$ & High confidence in TS and $\mathrm{V}_{\mathrm{LOS}}$ \\
\hline Very High & $>0.75$ & TS are more likely to fit the expected trend \\
\hline & Table 3: SAR Dataset Quality Index (SDQI)
\end{tabular}

1. Number of images Index (NI). This index (Table 4) assesses the impact of the number of available SAR images on the achievable coherent point density. Multi-temporal DInSAR processing produces more spatially dense and accurate results when applied to large datasets (CASU et al., 2006). Accordingly, this index increases with the number of acquisitions belonging to the SAR dataset. It is worth noting that a minimum number of SAR acquisitions, about 20 (e.g., MARINKOVIC et al., 2008; CROSETTO, 2011), opportunely distributed over time, should be considered to improve removal of atmospheric phase components from the stack of interferograms and generate reliable ground motion series. We assume that when the number of scenes composing the SAR dataset is lower than 20, this index is lower than 0.5 , and in this case DInSAR processing could be strongly affected by noise effects independently from the other indexes.

\begin{tabular}{cc}
\hline Number of Images & NI \\
\hline$<10$ & 0 \\
\hline $10-20$ & 0.25 \\
\hline $20-30$ & 0.5 \\
\hline $30-40$ & 0.75 \\
\hline$>40$ & 1 \\
\hline
\end{tabular}

Table 4: Number of images Index (NI) 
2. Time Index (TI): This index (Table 5) takes into account the time interval covered by the SAR dataset. In particular, in order to properly estimate and filter out seasonal trends (mostly due to atmospheric contributions), a time period sufficiently long should be considered. In addition, long deformation TS allow a better characterization of the temporal behaviour of the geological processes. For instance, to analyse swelling/shrinkage phenomena or landslides, TS should cover more than one seasonal cycle ( $>1$ year), and ideally be extended to several years to include both dry and wet years. However, long time period DInSAR analyses are affected by temporal "decorrelation" phenomena that reduce the number of coherent points (BONANO et al., 2012). Accordingly, TI takes into account these two opposite effects, reaching the maximum value for 5-8 year long analyses and decreasing for longer periods of investigation.

\begin{tabular}{cc}
\hline Temporal Span [years] & TI \\
\hline$<0.5$ & 0 \\
\hline $0.5-1$ & 0.25 \\
\hline $1-2$ & 0.5 \\
\hline $2-5$ & 0.75 \\
\hline $5-8$ & 1 \\
\hline $8-12$ & 0.75 \\
\hline$>12$ & 0.5 \\
\hline
\end{tabular}

Table 5: Time Index (TI)

3. Mean Temporal Baseline Index (MTBI): This index (Table 6) quantitatively assesses the impact of the mean temporal baseline (MTB) between consecutive SAR acquisitions, according to the following equation:

$$
M T B=\frac{\sum_{i=1}^{N-1}\left(T_{i}-T_{i-1}\right)}{N-1}=\frac{T}{N-1}
$$

Where

- $N$ is the number of available SAR images acquired at epochs $\left\{T_{0}, T_{1}, \ldots, T_{N-1}\right\}$,

- $\quad T$ is the whole temporal interval of the analysis, expressed in days.

MTBI is based on the average temporal baseline, in order to take in account the effect of very long temporal baselines that can occur in a very irregular temporal sampling.

\begin{tabular}{cccc}
\hline \multicolumn{3}{c}{ Mean Temporal Baseline } & MTBI \\
\cline { 1 - 3 } $\begin{array}{c}\text { L Band } \\
{[\text { Days }]}\end{array}$ & $\begin{array}{c}\text { C Band } \\
{[\text { Days }]}\end{array}$ & $\begin{array}{c}\text { X Band } \\
{[\text { Days }]}\end{array}$ & \\
\cline { 1 - 3 }$>360$ & $>120$ & $>60$ & 0 \\
\hline $180-360$ & $90-120$ & $45-60$ & 0.25 \\
\hline $90-180$ & $60-90$ & $30-45$ & 0.5 \\
\hline $60-90$ & $20-60$ & $15-30$ & 0.75 \\
\hline$<60$ & $<20$ & $<15$ & 1 \\
\hline
\end{tabular}

Table 6: Mean Temporal Baseline Index (MTBI)

MTBI considers that the effect of temporal "decorrelation" on different bands (L-, C-, and X-band) increases with decreasing wavelength (RocCA, 2007). Moreover, since larger wavelengths allow larger deformations to be estimated, 
lower values of the mean temporal baseline should be considered with C- and X-band SAR datasets with respect to Lband ones in order to limit phase unwrapping errors.

4. Mean Spatial Baseline Index (MSBI): This index (Table 7) takes into account the geometrical "decorrelation" effect, which depends on the critical perpendicular baseline computed according to the following equation (FRANCESCHETTI AND LANARI, 1999):

$$
\text { Bperp }_{\text {critical }}=\frac{\lambda r^{\prime}}{2 \Delta r}
$$

where:

- $\quad \lambda$ is the sensor wavelength;

- $\quad r^{\prime}$ is the sensor-target distance;

- $\quad$ and $\Delta r$ is the ground range resolution.

MSBI values (Table 7) were set on the basis of the critical spatial baseline for each band, considering the C-band ERS$1 / 2$ case as a reference (ground range resolution of $20 \mathrm{~m}$ and a sensor-target distance of $800 \mathrm{~km}$ ). In addition, the worst

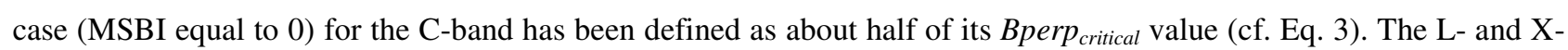
band values have been retrieved by scaling the C-band spatial baseline values with respect to wavelengths. It is worth noting that the impact of the ground range resolution on the critical baseline will be considered within the SRI described below.

By considering N SAR images, characterized by baseline values computed with respect to an acquisition chosen as reference, the mean spatial baseline (MSB) is calculated according to the following equation:

$$
M S B=\frac{B_{\max }-B_{\min }}{N-1}=\frac{B}{N-1}
$$

where $B_{\max }, B_{\min }$ and $B$ represent the maximum perpendicular baseline, minimum perpendicular baseline, and the orbital

\begin{tabular}{|c|c|c|c|}
\hline \multicolumn{3}{|c|}{ Mean Spatial Baseline } & \multirow[b]{2}{*}{ MSBI } \\
\hline $\begin{array}{c}\text { L-band } \\
{[\mathrm{m}]}\end{array}$ & $\begin{array}{c}\text { C-band } \\
{[\mathrm{m}]}\end{array}$ & $\begin{array}{l}\text { X-band } \\
{[\mathrm{m}]}\end{array}$ & \\
\hline$>1500$ & $>500$ & $>300$ & 0 \\
\hline $1250-1500$ & $400-500$ & $250-300$ & 0.25 \\
\hline $1000-1250$ & $300-400$ & $200-250$ & 0.5 \\
\hline $750-1000$ & $250-300$ & $150-200$ & 0.75 \\
\hline$<750$ & $<250$ & $<150$ & 1 \\
\hline
\end{tabular}
tube of the SAR dataset, respectively.

Table 7: Mean Spatial Baseline Index (MSBI)

5. Spatial Resolution Index (SRI): This index (Table 8) accounts for the impact of the ground range resolution

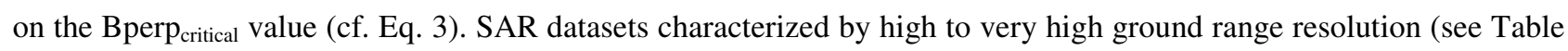
8) ease the detection of a larger number of measurement points, so that very spatially dense deformation maps can be produced (CALÒ et al., 2014). 


\begin{tabular}{llcc}
\hline Resolution & \multicolumn{1}{c}{ Satellite } & $\begin{array}{c}\text { Ground } \\
\text { Range } \\
\text { Resolution [m] }\end{array}$ & SRI \\
\hline Medium & ERS-1/2, ENVISAT, Standard Beam RADARSAT-1/2 & $>20$ & 0.25 \\
\hline Medium-High & Fine Beam RADARSAT-1/2, ALOS-1 & $7-15$ & 0.5 \\
\hline High & StripMap TerraSAR-X and COSMO-SkyMed & $3-7$ & 0.75 \\
\hline Very High & Spotlight TerraSAR-X and COSMO-SkyMed & $<3$ & 1 \\
\hline
\end{tabular}

Table 8: Spatial Resolution Index (SRI)

\subsection{Application and performance assessment}

We applied the proposed quality index SDQI to SAR datasets acquired by different satellites, at various frequency bands and spatial resolutions, over different study areas (Table 1 resumes all the parameters). Table 9 summarizes the computed SDQI indexes for the considered datasets. To ease the comparison, the SAR datasets are grouped by study area and processing technique. The average density of PS is used as parameter to assess the performance of SDQI. It's worth pointing out that radar target density depends also on characteristics of study area, e.g., land cover and topography (Table 9).

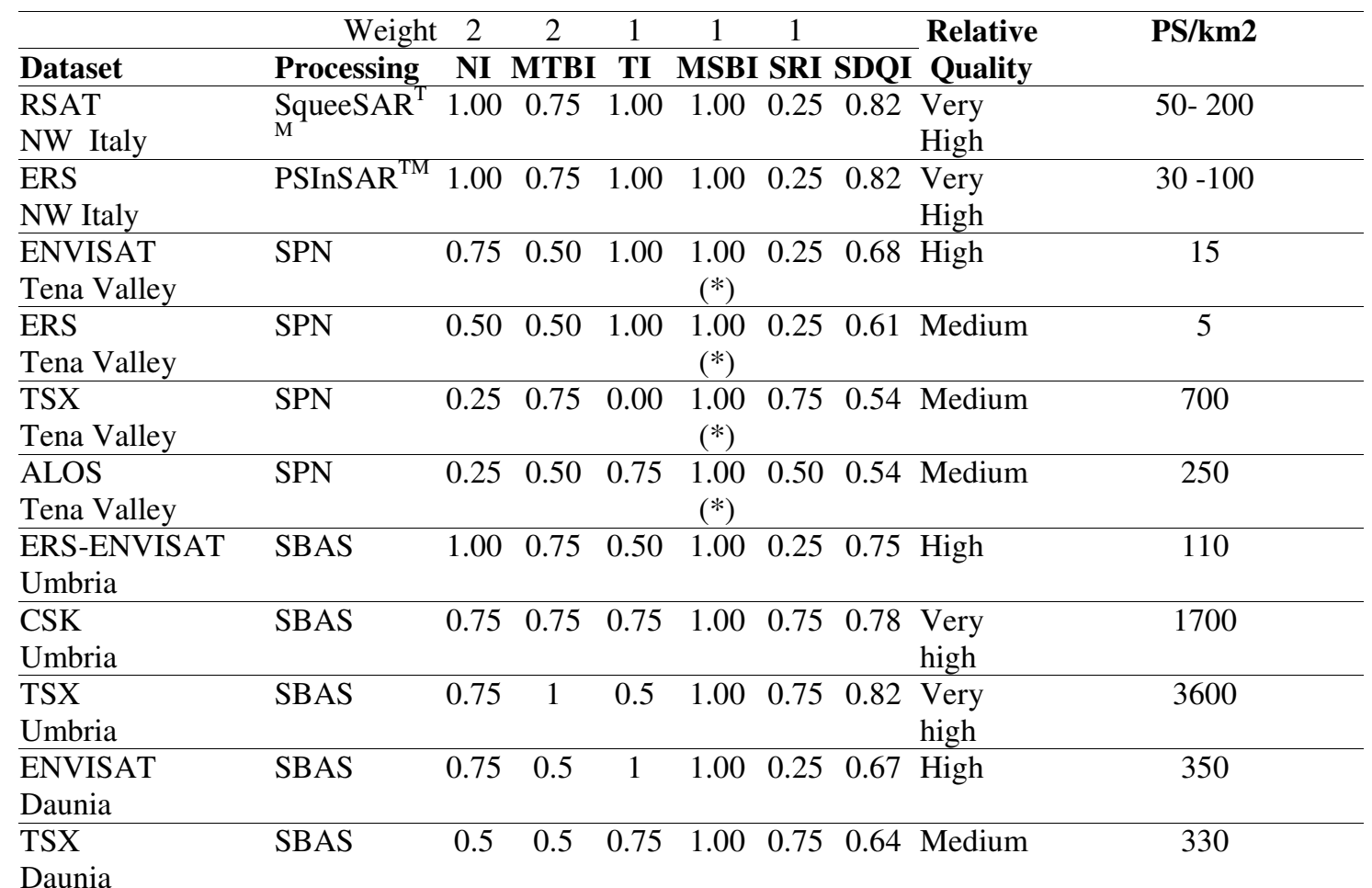

Table 9: SDQI calculation for selected case history datasets compared with the PS density (*) The data of MSBI was assumed equal to 1.0 on the base of PSI data producer indication.

The analysed data present usually good quality but in some cases (e.g. Tena Valley) the low SDQI values correspond to noisy TS (e.g. ALOS dataset Figure 2 C) or too short temporal spans (e.g. TerraSAR-X dataset Figure 2 D).

1) Tena Valley Spain. This area covers a medium steep mountainous area in Pyrenees. The main PS targets are represented by talus debris and some spare villages. Landslides are the main land surface processes that affect the area (HERRERA et al., 2013). All the datasets (ERS 1995-2000; EVISAT 2003-2007; ALOS 2006-2010; TerraSAR-X may - 
October 2008) were processed with SPN algorithm. In the case of ALOS dataset, the low amount of SAR images and the presence of 4-5 image gap (> 200 days) makes medium the overall quality of this dataset $(\mathrm{SDQI}=0.54,250$ $\mathrm{PS} / \mathrm{km}^{2}$ ), decreasing the level of confidence in using these TS for landslide hazard assessment. In the case of TerraSAR$\mathrm{X}$, even if the temporal baseline and the spatial resolution are good (11 images and revisiting time of 11 days), the observation period is too short (5/6 months), decreasing the dataset quality (SDQI $=0.54,700 \mathrm{PS} / \mathrm{km}^{2}$, ). ERS and ENVISAT (Figure $2 \mathrm{~B}$ ) datasets show better TS with medium (SDQI=0.61, $5 \mathrm{PS} / \mathrm{km}^{2}$ ) and high quality (SDQI=0.68; $\left.15 \mathrm{PS} / \mathrm{km}^{2}\right)$, respectively.

2) The NW Italy is covered by many datasets that presents almost the same characteristics in terms of number of images used, satellite and type of SAR processing (Table 1), as a result the SDQI is the same. Once we exclude the 1994 year gap from ERS-1/2 dataset processed by means of PSInSAR ${ }^{\text {TM }}$ the SDQI is very good (0.82), which is the same as for the RADARSAT-1 processed by means of SqueeSAR ${ }^{\mathrm{TM}}$ : this dataset covers the period 2003-2010 (Figure 2 A). The SAR point density range from 30 to $100\left(\mathrm{PS} / \mathrm{km}^{2}\right)$ for ERS and from 50 to $200 \mathrm{PS}-\mathrm{DS} / \mathrm{km}^{2}$ for Radarsat.

3) Umbria region, Central Italy. The landscape shows a hilly or mountainous morphology, with open valleys and large intra mountain basins. The area is widely affected by landslides and subsidence phenomena, with relevant impacts on urban areas and infrastructures. SAR Datasets (ERS-ENVISAT 1992-2010, COSMO-SkyMed 2009-2012, and TerraSAR-X 2011-2013) were processed by applying the SBAS-DInSAR approach. The data provided high quality TS for all datasets: SDQI=0.75, 110 Points $/ \mathrm{km}^{2}$ for ERS-ENVISAT, SDQI=0.78, 1700 Points/km² for COSMO-SkyMed and SDQI=0.82, 3600 Points $/ \mathrm{km}^{2}$ for TerraSAR-X.

4) Daunia Apennines (southern Italy). The study area is characterized by gentle hills and low mountains, only locally exceeding $1000 \mathrm{~m}$ above sea level. Complex mass movements widely occur in the region, heavily damaging villages and infrastructures. SAR datasets (ENVISAT 2003-2010, and TerraSAR-X January 2010 - June 2012) were processed by applying the SBAS-DInSAR approach. The data provided high quality TS for ENVISAT (SDQI=0.67, 330 Points $/ \mathrm{km}^{2}$ ), and medium quality TS for TerraSAR-X (SDQI=0.64, 350 Points $/ \mathrm{km}^{2}$ ).
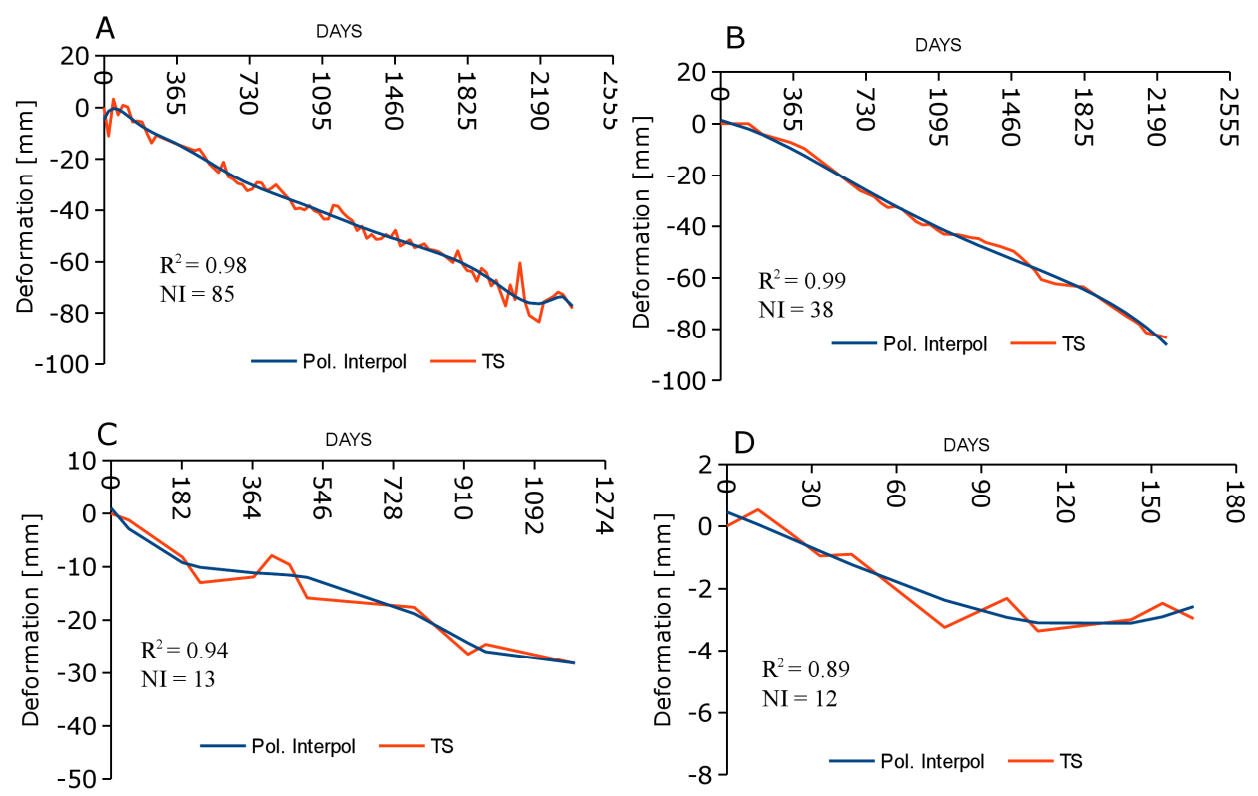

[Figure 2: An example of 4 Time series with similar rate of velocities $(-10 /-20 \mathrm{~mm} / \mathrm{yr})$ of 4 datasets with different SDQI. NI is the number of images A) RADARSAT descending dataset NW Italy, 85 images (temporal span 20032009), processed with SqueeSAR, SDQI = 0.81; B) ENVISAT descending datasets, Tena Valley, 38 images (temporal span 2001 - 2008) processed with SPN, SPN = 0.68; C) ALOS ascending dataset, Tena Valley, 13 images (temporal span 2006 -2010), SDQI = 0.54; TSX descending dataset, Tena Valley, 12 images (temporal span May-October 2008), $\mathrm{SDQI}=0.54$. It is possible to appreciate the best fit of TS with high SDQI to their polynomial interpolation.] 


\section{Post-Processing: Time Series improvement}

The post-processing analysis can be carried out to improve the quality of DInSAR data and correct possible errors. In literature it is possible to find works on TS error estimation working on process chain (HANSSEN, 2001). For instance GONZÁLEZ AND FERNÁNDEZ (2011) provide a model based on Monte Carlo methodology to asses the error in the time series during the processing steps related to atmosphere and develop a model to fit a non linear deformation. In this paper we provide a wider set of post-processing approaches that can be used also by SAR final user and oriented by ground truth observation. If the analysis of the time series does not show any particular noisy data, TS can be directly analysed as described in section 3 (i.e. trend analysis).

\section{1) Removing noise and regional trends}

The analysed DInSAR TS may be affected by trends or anomalous estimates not related to real ground motion. These trends are quite easy to detect because they usually affect the whole dataset. They can be due to different causes: errors in data processing (e.g., atmospheric phase screen);

- uncompensated orbital phase ramps

- regional trends related to long-term geological process (e.g., tectonic creep) onto which the local geological processes of interest (e.g., landslides, subsidence) overlap;

- presence of land movements at the reference point location that affect reversely all the dataset;

- thermal effects on targets: the difference of temperature between summer and winter can cause seasonal cycle of dilatation and shrinkage of target, especially if is a metallic object.

These errors can be identified by sampling all high coherence $(>0.9)$ radar targets from a selected stable area where LOS average velocities are in the range $\pm 0.5 \mathrm{~mm} / \mathrm{yr}$. The stable area can be choice for instance on the base of GPS data if available, or using ancillary geomorphological knowledge on the area. TS of these targets are averaged at each date of the monitoring period, and if the averaged TS reveals the presence of specific trends (e.g., seasonality), the whole dataset is probably affected by an artefact. It is possible to remove the artefact from the $i$-th TS of the DInSAR dataset of interest (i.e. $\mathrm{TS}_{\mathrm{i}}$ ), through simple subtraction of the averaged $\mathrm{TS}$ of the stable, coherent targets (i.e. $\mathrm{TS}_{\text {Noise }}$ ). This allows to compute the corrected TS (i.e. $\mathrm{TS}_{\mathrm{c}}$ ):

$$
\mathbf{T S}_{\mathbf{c}}=\mathbf{T S}_{\mathbf{i}}-\mathbf{T S}_{\text {Noise }}
$$

Figure 3 shows an example of RADARSAT-1 TS ascending data processed with SqueeSAR ${ }^{\mathrm{TM}}$ algorithm over Liguria Region. As clearly shown, the original TS data reveal strong seasonality. This trend is common to all the TS of this dataset, including very stable and high coherence PS and Distributed Scatterers (DS) of the dataset, so it is suggested that the observed seasonality relates to an artefact. The seasonal trend (black dot line) is obtained by averaging TS of stable (Vlos in the range $\pm 0.5 \mathrm{~mm} / \mathrm{yr}$ ) and high coherence (coher>0.9) PS and DS of the SqueeSAR ${ }^{\mathrm{TM}}$ dataset. Then the extracted seasonal trend is subtracted from the original TS to remove the artefact, which helps to obtain less noisy TS (red line in Figure 3). 


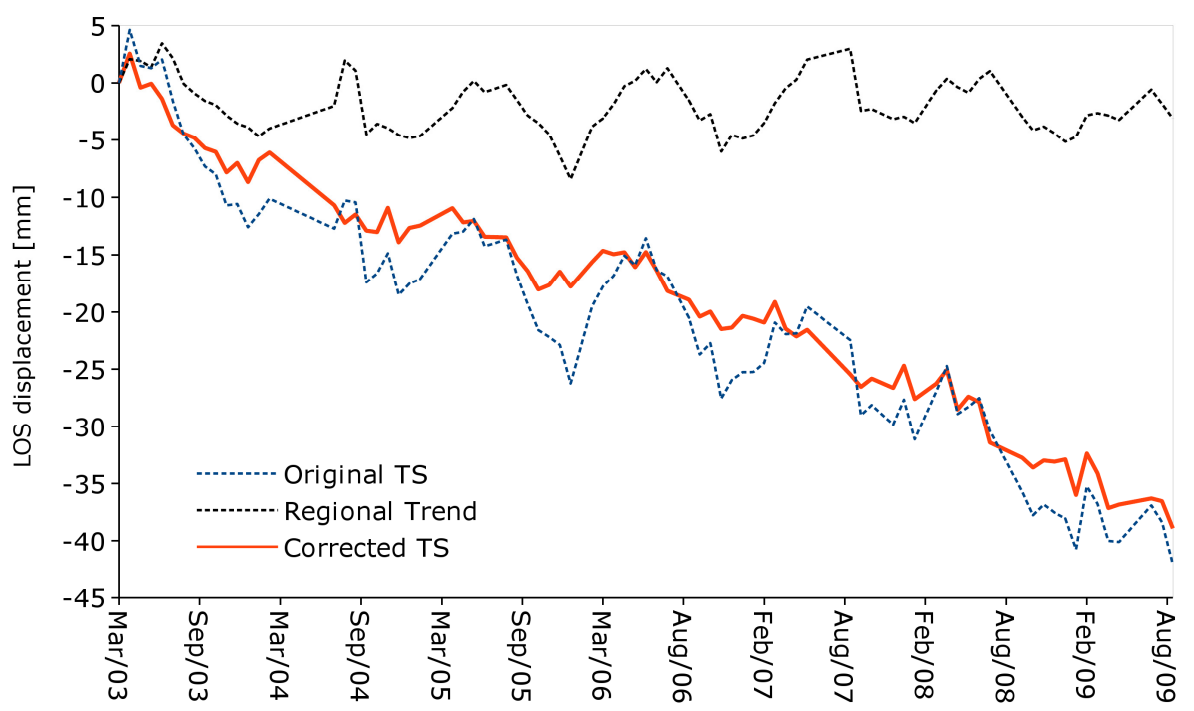

[Figure 3: Removal of regional trend from TS data from the RADARSAT-1 SqueeSAR ${ }^{\mathrm{TM}}$ ascending data available for Liguria Region, Italy. It is possible to appreciate the decrease on noise in de-trended time-series. ]

\section{2) Removing single date anomalies}

Another typology of error that can be observed during the analysis of DInSAR TS is related to anomalous displacement estimates recorded at a certain date of the monitoring period, and spatially diffused across the whole dataset of DInSAR targets. In order to detect such errors, stable $( \pm 0.5 \mathrm{~mm} / \mathrm{yr})$ and high coherence ( $>0.9)$ TS can be selected from the dataset, similarly to the above described approach for the removal of regional trends. If more than one third of the selected TS shows high dispersion in the displacement value (e.g., $> \pm 5 \mathrm{~mm}$ from TS regression line for $\mathrm{X}$ and C-Band; $> \pm 15 \mathrm{~mm}$ for L-band) at the same date of acquisition, it is recommended to remove from the dataset the anomalous date to avoid misleading interpretations like unwrapping errors described in the next tools.

An example of this error was found in the RADARSAT-1 descending dataset "Dogliani" processed with SqueeSAR ${ }^{\mathrm{TM}}$ for the Langhe Hills in NW Italy. In particular, on 07/01/2009 more than one third of the selected TS exceed the $\pm 5 \mathrm{~mm}$ threshold. The anomalous values at that acquisition time might be related to snowfall occurred on the day of the SAR acquisition (see the sample PS in Figure 4). Consequently it is suggested that this scene is removed and not included in the TS analysis.

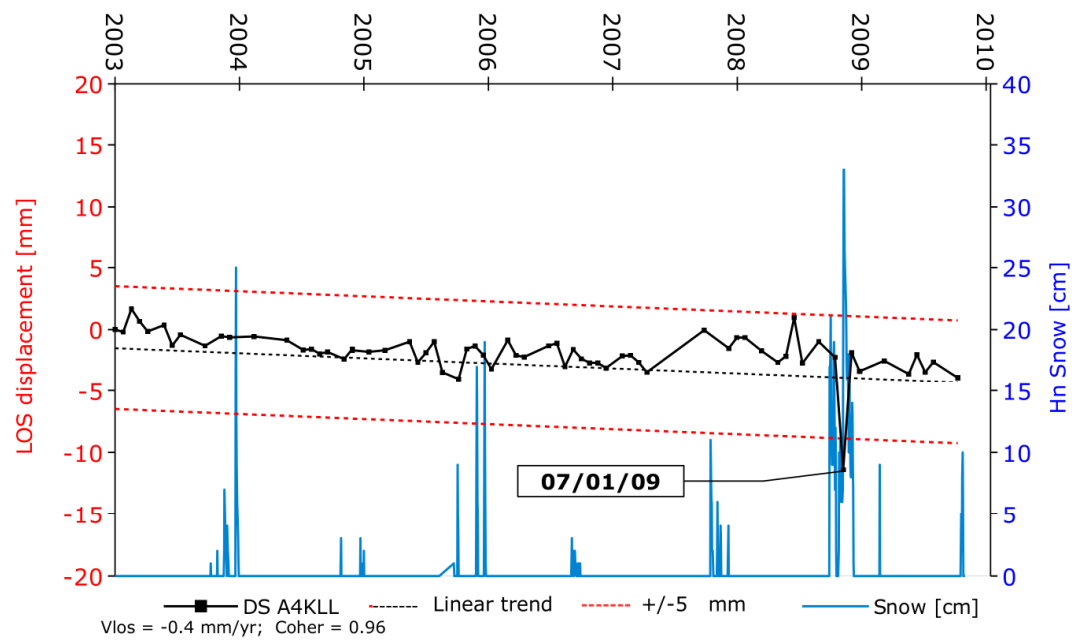

[Figure 4: Example of stable TS $(-0.4 \mathrm{~mm} / \mathrm{yr})$ (Langhe Hill dataset) exceeding the $\pm 5 \mathrm{~mm}$ threshold at the date 7/01/2009, compared with snow height observed at ground (Hn) (Source Hydrological database ARPA Piemonte)] 


\section{3) Detect and correct possible phase unwrapping errors}

One of the limitations of DInSAR techniques is related to possible phase unwrapping errors caused by more than a quarter of the radar wavelength motions occurring between two successive acquisitions or two close targets of the dataset (e.g., CROSETTO et al. 2010). We propose an empirical methodology to detect and mitigate potential phase unwrapping errors during the post-processing stage using a semi-quantitative approach on a simple TS plot.

Especially when working with landslides, it is possible to observe sudden motions occurring at specific dates of the monitoring interval (e.g., rapid movement along unstable slopes). Since these motions may be related to anomalies at specific acquisitions, it is necessary to remove other possible sources of errors from the dataset (as described in the previous section) before checking for unwrapping errors. If the absolute difference of the displacement (D) observed between two consecutive acquisitions $\left(t_{i}\right.$ and $t_{i+1}$ ) exceeds the phase ambiguity $\lambda / 4$ (e.g. $14 \mathrm{~mm}$ for C-band data) it is possible to "jump" to the proposed replica (up or down) of TS that is placed at $\pm \lambda / 2$.

IF $\mathrm{D}_{(\mathrm{ti}+1)}-\mathrm{D}_{(\mathrm{ti})}>\lambda / 4 \rightarrow \mathrm{D}_{(\mathrm{ti}+1)}-\lambda / 2$ (correction for decreasing TS)

IF $D_{(\mathrm{ti}+1)}-\mathrm{D}_{(\mathrm{ti})}<-\lambda / 4 \rightarrow \mathrm{D}_{(\mathrm{ti}+1)}+\lambda / 2$ (correction for increasing TS)

Before to apply the jump it is important to take in account some limitations:

- in order to validate the jump to the replica it is necessary to have external sources of data, for instance, other monitoring measures, rainfall data, evidence of acceleration from field survey or literature.

- the tool can ease the correction of one unwrapping error.

Using a simple plot of TS it is possible to graphically see the conceptual model of this correction. In Figure 5 an example of TS affected by this type of error is shown for a landslide in the Langhe hills (NW Italy). The PS and DS data were generated from RADARSAT-1 imagery processed with SqueeSAR ${ }^{\mathrm{TM}}$ and are located close to the crown of the landslide reactivated in April 2009 (Figure 5A). In figure 5 B it is shown the time-series and the error bars of $\pm \lambda / 4$ $( \pm 14 \mathrm{~mm})$ and the real displacement between two consecutive acquisition (green dots). If the displacement is larger than $\lambda / 4$ the green dots fall outside the errors bars and it can represent a possible case of phase unwrapping error. The TS studied from 2006 show weak movement until 2008 then from December 2008 it is possible to see a strong acceleration of the movement until April 2009 then followed by a positive Jump. Between April 2009 - July 2009 the displacement it was larger than $+\lambda / 4$. After a check with ground truth incandescence it was decided to apply a correction of $-\lambda / 2$. From a qualitative point of view, with this correction the trend is more reliable with the possible landslides acceleration even if in terms of absolute movement also this correction may underestimate movement because we do not know how many $\lambda / 2$ jumps are occurred. The acceleration occurred from December 2008 to April 2009 well fit the cumulated rainfall and can explain the paroxysmal event occurred at the end of April 2009. This ground deformation behaviour better depicts the observation based on rainfall data and the expected motion of the landslide in response to the triggering factor. The landslide body has no PS because the movement was too rapid to guarantee sufficient phase correlation during the monitoring interval (on the order of several meters). 


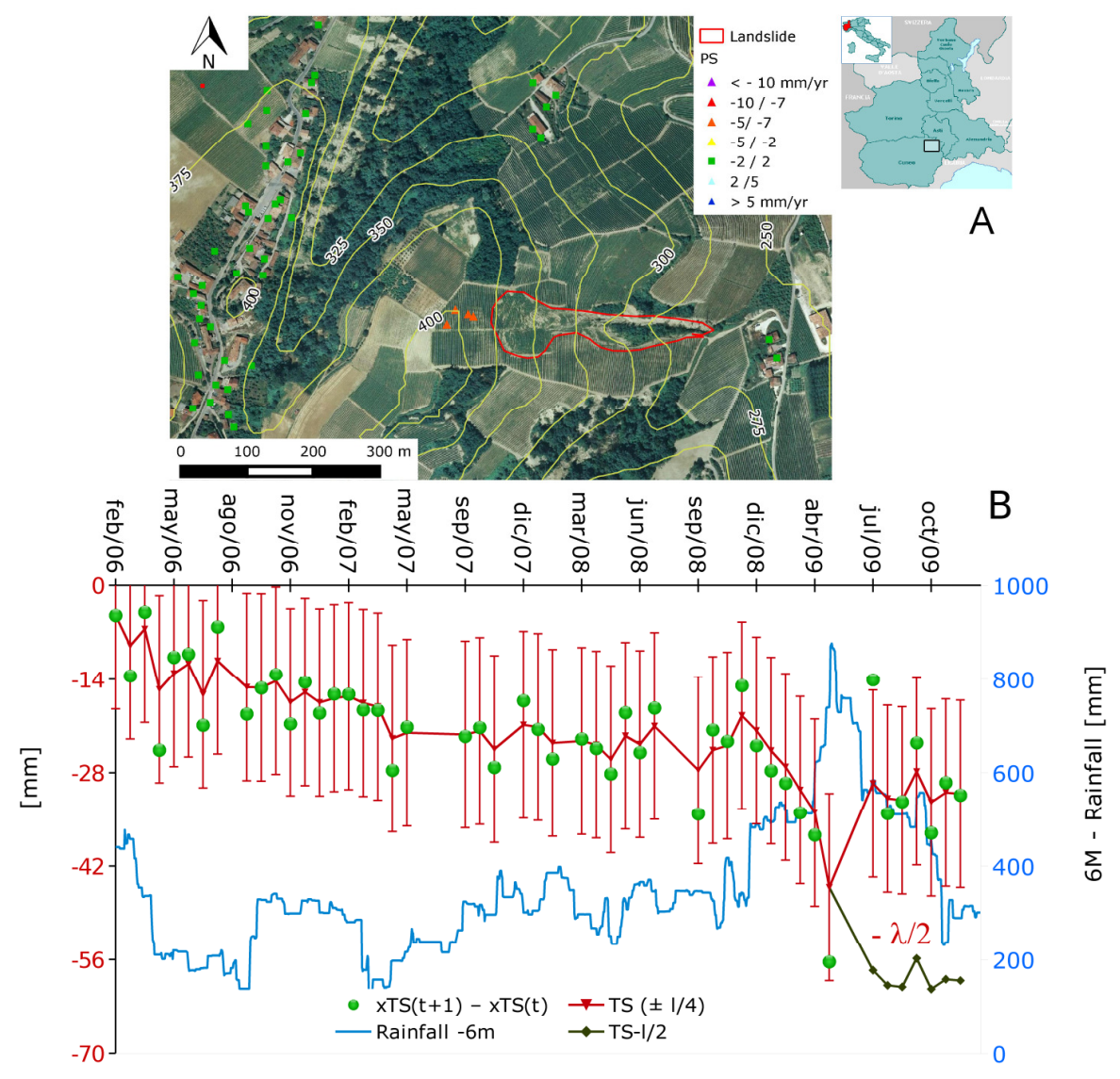

[Figure 5: A) Location of the case history; B) The standard time-series with its error bars of $+/-\lambda / 4(14 \mathrm{~mm})$ the green dots represent the differential displacement between two consecutive acquisition $\left(\mathrm{xTS}_{(\mathrm{t}+1)}-\mathrm{xTS}_{(\mathrm{t})}\right)$. If the the differential displacement is bigger than $|\lambda / 4|$ the green dot it is outside of TS errors bars (red) and it is possible to introduce a $\lambda / 2$ correction (e.g. April - July 2009)]

\section{4) Averaging Time Series}

When the distribution of annual velocities across the monitored area appears noisy and difficult to interpret, TS can be spatially averaged to better detect the general trends of deformations. This can be done, for instance, for the TS located in the same geomorphological unit, which fall within a single landslide or in a subsiding area which are thought to be characterised by similar ground motion velocities.

The averaging procedure helps to smooth the spatially variable velocities referring to single targets. Moreover, the comparison between the averaged TS and single PS or DS can be used to find processes possibly occurring at the local scale.

Figure 6 shows the case of the Mendatica landslide in the Ligurian Alps in Italy. It is possible to identify 33 PS and DS in the upper part of the landslides with velocity in the order of 8-12 mm/yr. Clearly, the TS of single PS or DS present higher variance $(5.8 \mathrm{~mm} / \mathrm{yr})$ with respect to the averaged TS $(2.5 \mathrm{~mm} / \mathrm{yr})$, and the averaging procedure reveals the general trend of the TS that shows a strong acceleration of landslide motions in 2008. 

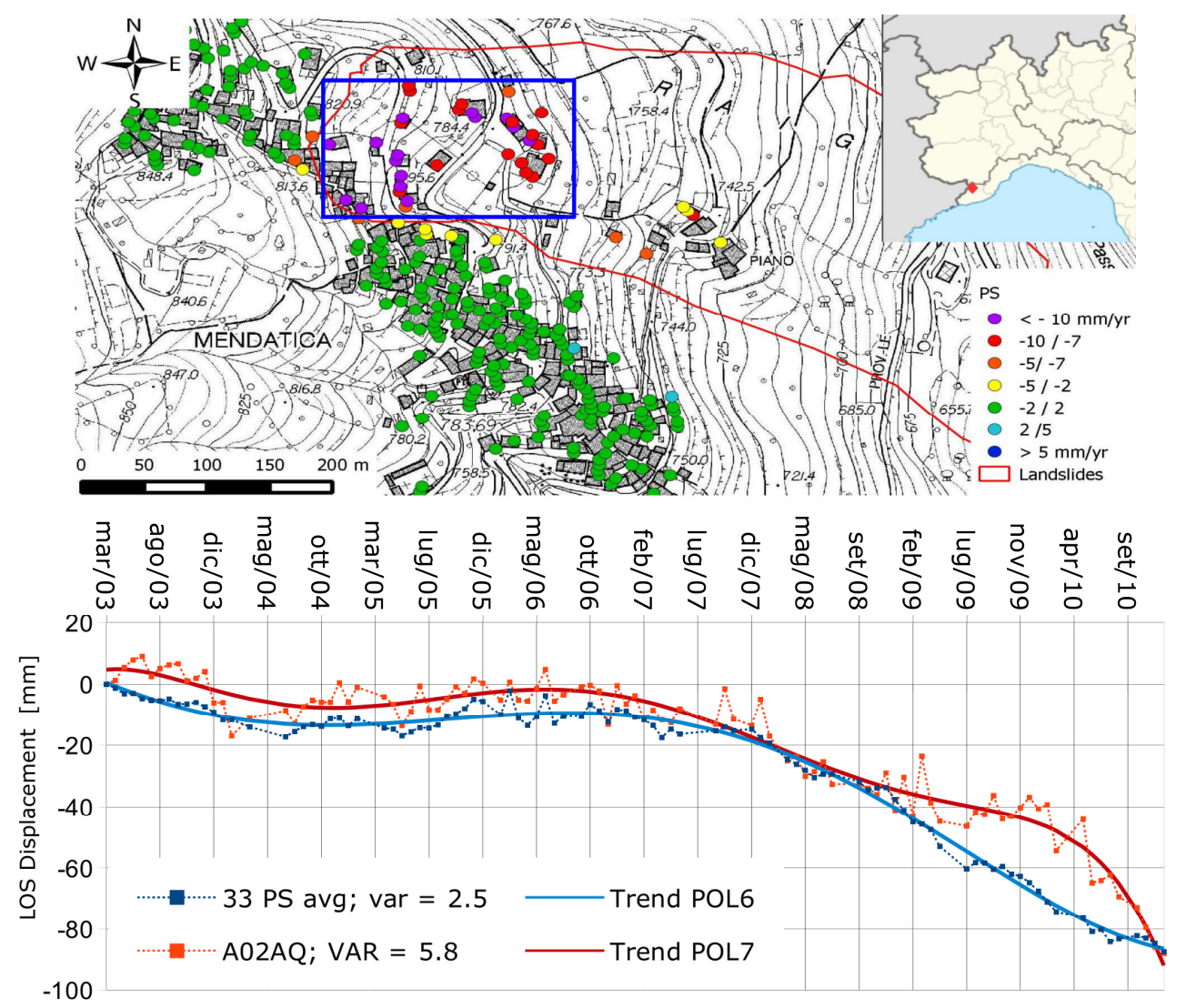

[Figure 6: Mendatica landslides. Comparison between single TS and 33 averaged TS. It is possible to see the reduction of the noise and easier identification trends. ]

\section{TS classification, identification of trends and deviations}

Following the reduction of noise and quality improvement (see section 2), the analysis of DInSAR TS proceeds with the identification and classification of temporal trends in high to very high quality TS datasets. Attention should be paid, however, not to misinterpret 'artificial' or residual trends by considering these as true ground movements. Identification of trend deviations in DInSAR TS is crucial to understand geological processes. The recent literature reports on some methodologies to overcome limits related to manual, visual analysis and classification of TS (e.g., BERTI et al., 2013; CIGNA et al., 2012). These methods can support radar-interpreters during their analysis of large DInSAR datasets, to identify critical areas of concern, non-linearity, acceleration/deceleration and, more generally, any deviations from $a$ priori defined trends.

We implement here the following approaches (Table 10):

1) PS-Time: BERTI et al. (2013) developed 'PS-Time', an automatic classification tool for PS TS based on a conditional sequence of statistical tests. This tool allows identification of six trend types (i.e. uncorrelated, linear, bi-linear, quadratic, and discontinuous with constant and variable velocity), and additional parameters, such as the break date (date identifying the trend change), $V_{l}, V_{2}$ (the motion rate after and before the trend change), and the index BICW (showing the degree of bi-linearity of TS). PS-Time can support both regional and local scale studies of large PS datasets, and be particularly efficient when the behaviour of the geological process under investigation is unknown. PSTime is freely accessed at http://www.bigea.unibo.it/it/ricerca/pstime.

2) Deviation Index (DI) and mobile DI: Cigna et al. (2012) developed the Deviation Index (DI), able to quantify trend deviations within DInSAR TS by reproducing the visual process of identification of trend changes. The first type 
of DI (i.e. DI1) quantifies the deviation recorded after a certain date $t_{b}$ with respect to its prediction based on the linear regression of the TS records before $t_{b}$, whilst the second type (i.e. DI2) compares the TS behaviour before and after an event occurred at $t_{b}$, by measuring any displacements recorded at $t_{b}$ and identifying its impact on the TS. The use of DI1 and DI2 can support both local and regional analyses of DInSAR TS, when an event is thought to have an impact on the ground motion trend, either permanently after a $t_{b}$, or only temporarily at $t_{b}$. Since the application of the DI requires $t_{b}$ selection to cut the TS into two distinct subintervals to compare, building upon the original method by CIGNA et al. (2012), TAPETE AND CASAGLI (2013) developed the "mobile DI" approach to identify objectively the correct break date. This method consists in the computation of the DI across the entire monitoring period followed by analysis of DI variations as a function of changing $t_{b}$. The approach can be used when $t_{b}$ cannot be defined $a$ priori as no background information about the process to study is available. The main advantages of the mobile DI are both the confirmation of the suitability of a fixed $t_{b}$, and the identification of other possible dates acting as temporal breaks, which were not previously identified by visual inspection.

3) Velocity TS: With this tool it is possible to generate temporal series of velocity from DInSAR TS, by cutting the monitored period into regular sub-intervals and extracting partial linear regressions on the displacement data. Number and length of the sub-intervals can be determined by accounting for: (i) TS quality, which is influenced by temporal span and number of displacement records composing the sub-interval (generally, the shorter the length of the subintervals or lower the number of scenes, the higher the likelihood that the resulting series of velocities will appear noisy; as practical recommendation, TS averaging may be implemented beforehand, and sub-intervals should include at least 5-6 displacement records; see section 2.3); and (ii) the deformation trend of the studied phenomenon, that can be identified via preliminary visual inspection of the TS (e.g., either long-term or season-based sub-intervals may be considered).

\begin{tabular}{|c|c|c|}
\hline Methodology & Objectives & Applications \\
\hline $\begin{array}{l}\text { PS-Time } \\
\text { (BERTI et al., } \\
\text { 2013) }\end{array}$ & $\begin{array}{l}\text { Automated detection of trend typologies for each } \\
\text { TS of the analyzed dataset, and additional } \\
\text { parameters. }\end{array}$ & $\begin{array}{l}\text { Regional and local scale analysis of large } \\
\text { DInSAR dataset, when the deformation } \\
\text { behaviour and the date of the event of the } \\
\text { studied process are unknown. }\end{array}$ \\
\hline \multirow{2}{*}{$\begin{array}{l}\text { Deviation Index, } \\
\text { DI (CIGNA et al., } \\
\text { 2012a) }\end{array}$} & $\begin{array}{l}\text { DI type } 1 \text { (DI1): Quantification of the deviation } \\
\text { within TS after a certain date } t_{b} \text {, with respect to } \\
\text { its prediction based on the 'historical' pattern. }\end{array}$ & $\begin{array}{l}\text { DI type } 1 \text { (DI1): Local and regional scale } \\
\text { applications, when events of known date } \\
\text { occurred and have changed the general trend } \\
\text { of the TS. }\end{array}$ \\
\hline & $\begin{array}{l}\text { DI type } 2 \text { (DI2): Quantification of the sudden } \\
\text { trend change occurred at the date } t_{b} \text {, by } \\
\text { evaluating the step recorded at } t_{b} \text { within the } \\
\text { series, not necessarily associated with an overall } \\
\text { trend change. }\end{array}$ & $\begin{array}{l}\text { DI type } 2 \text { (DI2): Local and regional scale } \\
\text { applications, when events of known date } \\
\text { occurred and have changed the TS locally } \\
\text { and in the immediate of the event (e.g., } \\
\text { sudden displacement), but not its general } \\
\text { trend. }\end{array}$ \\
\hline $\begin{array}{l}\text { Mobile DI } \\
\text { (TAPETE \& } \\
\text { CASAGLI, 2013) }\end{array}$ & $\begin{array}{l}\text { Retrieval of the curve of DI vs. } t \text { to identify } \\
\text { peak values due to trend deviation or changes } \\
\text { throughout the TS. In doing so, it complements } \\
\text { the DI approach. }\end{array}$ & $\begin{array}{l}\text { Local and regional scale applications, when } \\
\text { the deformation behaviour and the date of the } \\
\text { event of the studied process are either known } \\
\text { or unknown. }\end{array}$ \\
\hline $\begin{array}{l}\text { Velocity time } \\
\text { series }\end{array}$ & $\begin{array}{l}\text { Evaluate the temporal variation of the velocity, } \\
\text { by cutting TS into sub- intervals and re- } \\
\text { computing step-wise velocities. May underline } \\
\text { seasonal components. }\end{array}$ & $\begin{array}{l}\text { Local scale analysis, when long and not } \\
\text { noisy TS are available. To reduce noise a } \\
\text { spatial averaging of TS is recommended. }\end{array}$ \\
\hline
\end{tabular}

Table 10: Comparative summary of the approaches of trend analysis of DInSAR time series tested in this research.

We applied the above three methodologies to analyse two test areas in Italy: (1) Pontecurone, in Piemonte Region, NW Italy, affected by land subsidence, and (2) Crociglia landslide, NW Apennines. 
For both sites, two SAR data stacks processed by TRE S.r.l. with the SqueeSAR ${ }^{\mathrm{TM}}$ algorithm (FERRETTI et al., 2011) were employed:

- 89 RADARSAT-1 Standard Beam, ascending mode images (24/03/2003-22/05/2010);

- 84 RADARSAT-1 Standard Beam, descending mode images (28/04/2003-05/10/2009).

\subsection{Subsidence case history of Pontecurone}

Pontecurone is a small rural village in the southwestern sector of the Po River Plain, located on the alluvial fan of Curone stream (Figure 7), where thickness of alluvial sediments exceeds $150 \mathrm{~m}$. Stratigraphic and geotechnical data for the region show a typical alluvial succession of gravel, sand (aquifer layer) and silt-clay (aquitard layers); in Pontecurone clay sediments (at least 10m thick) outcrop and locally confine the first aquifer (Figure 7). In the upper part of Curone alluvial fan, several groundwater wells exploit confined aquifers, and are generally deeper than those in the northern sectors. Though there is little information available about water extraction, groundwater exploitation seems to be mainly related to agricultural irrigation.

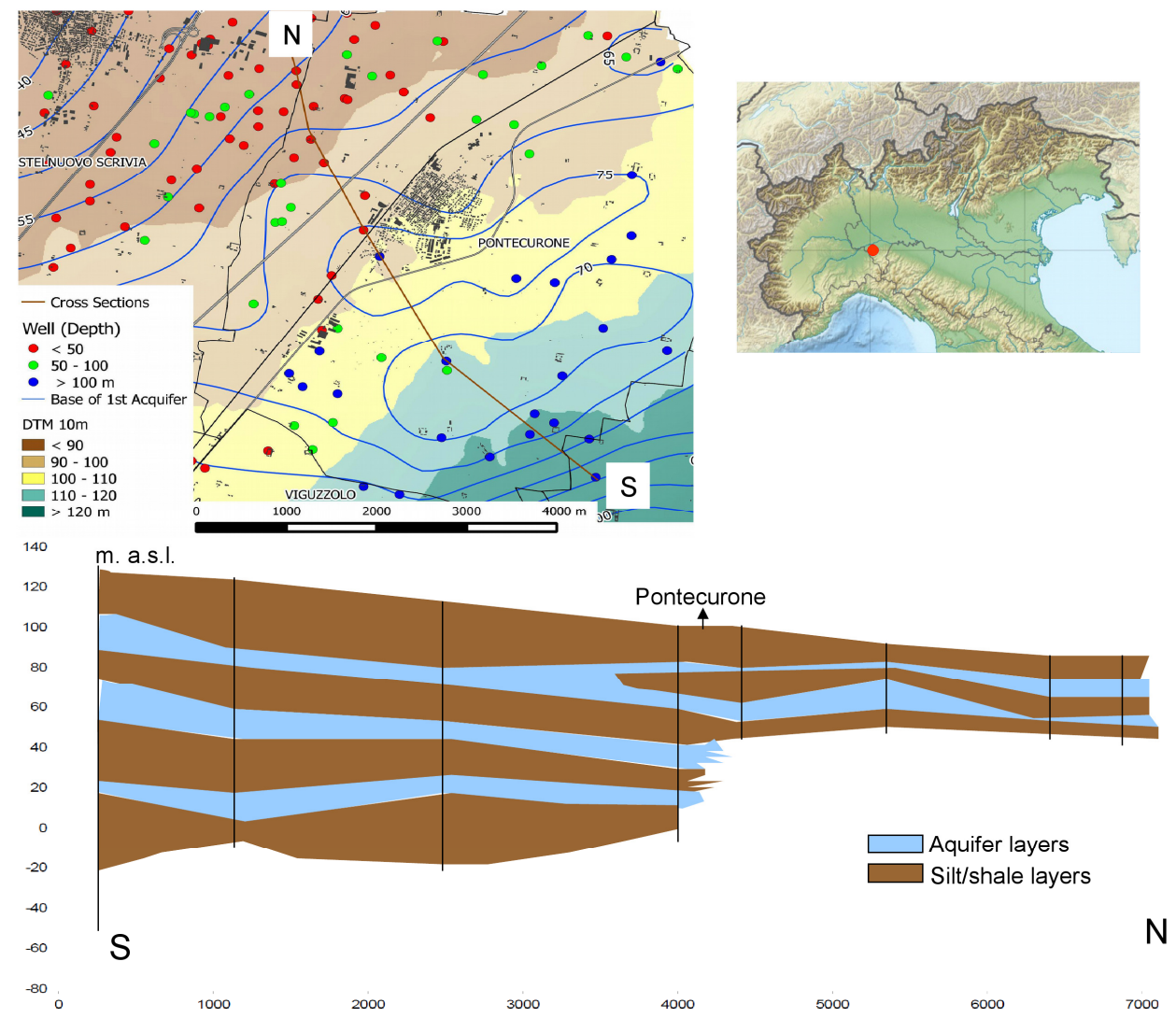

[Figure 7: Simplified hydro-geological setting of Pontecurone. It is possible to see that the area at south of the village is characterized by the presence of deep borehole. Borehole data from Provincia Alessandria / Regione Piemonte Settore Acque]

Visual analysis of the annual LOS velocity $\left(\mathrm{V}_{\mathrm{LOS}}\right)$ of both ascending and descending SqueeSAR ${ }^{\mathrm{TM}}$ RADARSAT-1 datasets, revealed general stability of the area, with only two confined zones in Pontecurone and Voghera showing motion rates down to $-5 \mathrm{~mm} / \mathrm{yr}$ (Figure $8 \mathrm{~A}$ ).

Automatic TS classification of over 28,000 points of the SqueeSAR ${ }^{\mathrm{TM}}$ ascending and 23,000 points of the descending TS datasets with PS-Time showed that in the area of Pontecurone most TS are classified as bi-linear, especially within the ascending dataset while, for the remainder of the dataset, the typology of TS are either linear or uncorrelated, and 
only a few are classified as quadratic (Figure $8 \mathrm{~B}$ ). The BICW index showed for the area of Pontecurone values higher than 1.2, this indicating the occurrence of strongly bi-linearity, and identified the break date of the TS in the last part of 2008 , i.e. $27 / 11 / 2008$.

The computation of the DI1 confirms this evident change of trend in the TS of both ascending and descending data. By assuming November 2008 as the $t_{b}$ for all the series, the resulting DI1 (Figure $8 \mathrm{C}$ ) show that the extension of the area affected by temporal deviations is by far wider than that depicted by the sole visual analysis of annual $\mathrm{V}_{\mathrm{LOS}}$. The DI1 results for the descending dataset (Figure $8 \mathrm{C}$ left) highlight that large sectors of the scene recorded deviations as high as 1.5 to 3 times the respective predictions based on the temporal history of the area before $t_{b}$. More than half of the built-up area of Voghera, indeed, evidences DI1 values of 1.5-3.0 and even higher than 3.0-5.0 for a small sector in the southwestern outskirts of the town. Pontecurone, Casei Gerola and Rivanazzano Terme show DI1 greater than 1.5. The DI1 computation for the ascending dataset (Figure $8 \mathrm{C}$ right) also shows concentration of trend deviations over Pontecurone, with DI1 increasing by moving from the outskirts to the centre of the village.

It is worth noting that the ascending and descending mode TS are characterized by both different time lengths and different number of scenes composing the input satellite image stacks, as mentioned above. The use of a common $t_{b}$ for both datasets creates TS sub-samples with different lengths of the historical (i.e. pre- $t_{b}$ ) and updated (i.e. post- $t_{b}$ ) intervals in ascending and descending mode. In particular, while the length of the updated interval is 16-image long for the ascending data, this is only 10-image long for the descending one, hence the computation of DI1 for the latter is less reliable, due to the fewer number of scenes available after $t_{b}$.

To confirm the suitability of the fixed $t_{b}$ and identify possible additional dates of trend deviation, the mobile DI was also calculated over the entire TS for both PS and DS of the ascending dataset over the village of Pontecurone where, as above discussed, a clear pattern was identified in the spatial distribution of the DI1 (Figure 8C-9A). The example in Figure 9 refers to the DS A4WEI in the northeastern quarter of the village where the highest values of DI1 at the selected $t_{b}$ (2.8 to 5.3) were retrieved. The TS of the examined DS is characterized by an inversion of the trend (i.e. from moving away from the satellite to moving towards it) immediately after the $t_{b}$ suggested by PS-Time and confirmed by the DI1 (Figure 9 C). The curve of the mobile DI1 gives an objective confirmation (Figure 9 D), with the main peak reaching 5.6 on 10/12/2008, and also adds evidence not retrieved by visual inspection of the TS. Indeed, after $t_{b}$ another DI1 peak of $\sim 5.0$ is identified on 11/11/2009 (Figure 9 D), i.e. in correspondence with a trend change occurred within the post- $t_{b}$ sub-interval (Figure $9 \mathrm{C}$ ). This peak marks a further acceleration of the LOS displacements exactly one year after the occurrence of the main trend inversion (i.e. 10/12/2008). Moreover, an additional DI1 peak occurs at the end of 2007 - early 2008, i.e. almost one year prior to the main trend inversion. Though less pronounced (DI1 of 4.2), this peak could indicate an early temporal break that sole visual inspection of the TS likely would have not identified.

The evidence discussed above with regard to DS A4WEI is also found within the TS of the neighbouring PS and DS, and therefore relates to instability affecting the entire local area in Pontecurone.

The computation of the TS of the LOS velocities was performed on the averaged TS of both the SqueeSAR ${ }^{\mathrm{TM}}$ ascending and descending datasets, for the area where the DI1 spatial distribution showed the highest values. The velocity calculated for the two periods, preceding and following $t_{b}$, confirms observations based on the first two methodologies, and shows land subsidence at -3 to $-5 \mathrm{~mm} / \mathrm{yr}$ rates occurring between 2003 and 2008, followed by 10 $\mathrm{mm} / \mathrm{yr}$ uplift (Figure 10). By computing the velocity TS over 6-month long intervals, seasonal components can be recognised and, in particular, we identify negative LOS velocities until October/November, which are followed by periods of uplift in winter and early spring. Between 2003 and 2008, land subsidence seems stronger than uplift, whereas in the following period (between 2008 and 2010) the opposite is observed. The long-term trend across the full 
TS confirms the bi-linear trend detected by PS-Time automated classification, as well as the high DI1 values observed within this sector of the processed area.
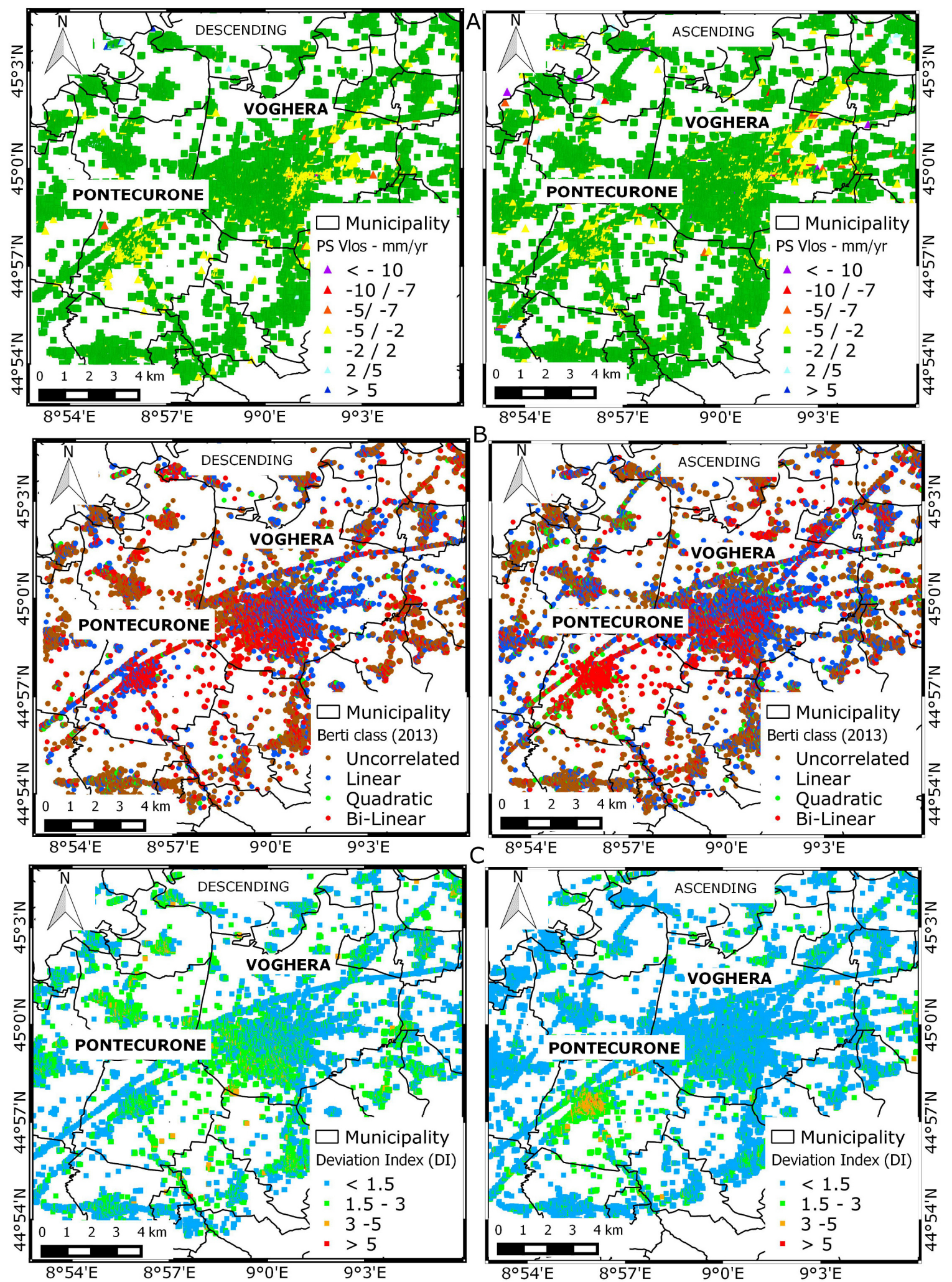

[Figure 8: RADARSAT-1 SqueeSAR ${ }^{\mathrm{TM}}$ time series over Voghera and Pontecurone. A) LOS velocities for descending (left) and ascending (right) mode data processed with SqueeSAR ${ }^{\mathrm{TM}}$ by TRE S.r.l.; B) Automated classification in descending (left) and ascending (right) mode, based on PS-Time classification tool by BERTI et al., 2013; C) Semiautomated classification descending (left) and ascending mode, based on the Deviation Index (DI) approach by Cigna et al. (2012).] 
The most likely cause of the observed seasonality is related to groundwater oscillations due to extraction from deep and confined aquifers for agricultural use (Figure 10), consequent variation of pore water pressure and ground settlement and/or heave. Maximum water levels are reached in spring, while minimum levels in early autumn, after irrigation. Long-term oscillations are related to wet and dry periods, e.g., from 2003 to 2008 a drier period caused general decrease of water levels, whereas from 2009 to 2010 a wetter period caused general increase of piezometric levels.
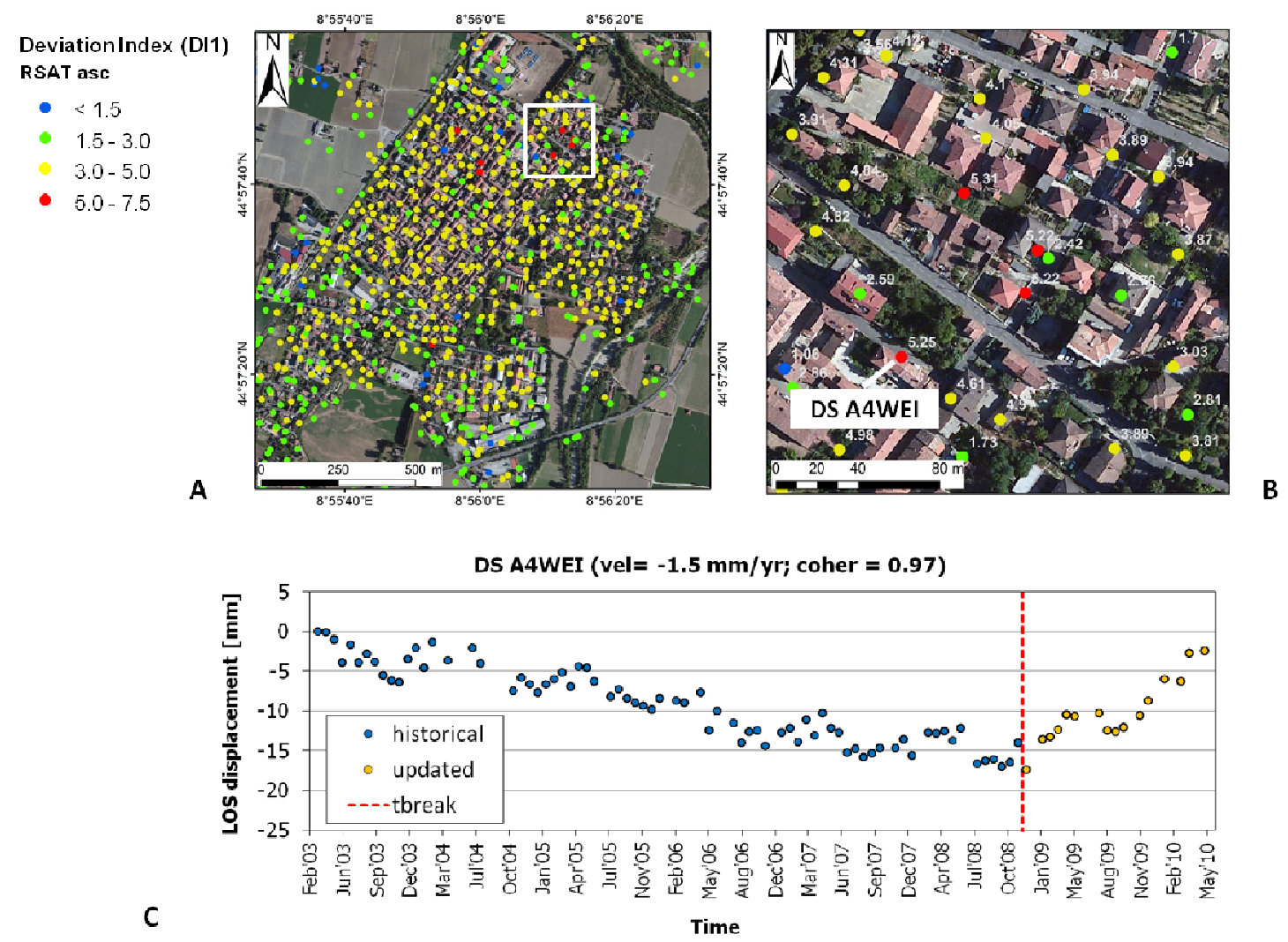

C

Time

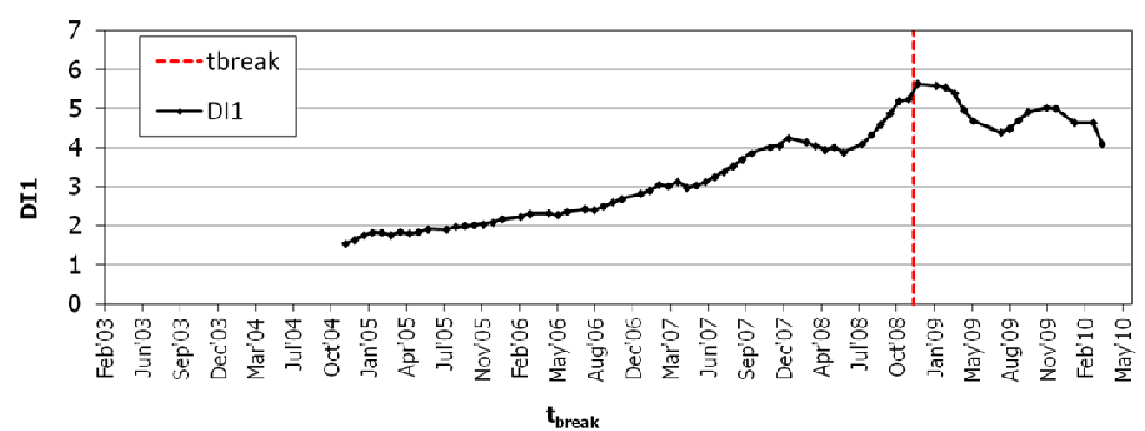

[Figure 9: A) Semi-automated classification of RADARSAT-1 SqueeSAR ${ }^{\mathrm{TM}}$ ascending time series based on DI1 over the village of Pontecurone (cf. Figure 8 C) overlapped onto Virtual Earth image (Bing Maps (C) 2013 Microsoft Corporation), with indication of the north-eastern quarter (see white square), where B) the highest values of DI1 were retrieved (range: $2.8-5.3$ ). C) Time series and D) graph of DI1 vs. $t_{b}$ for the DS A4WEI. Red dashed line marks the a priori $t_{b}$ in November 2008.] 


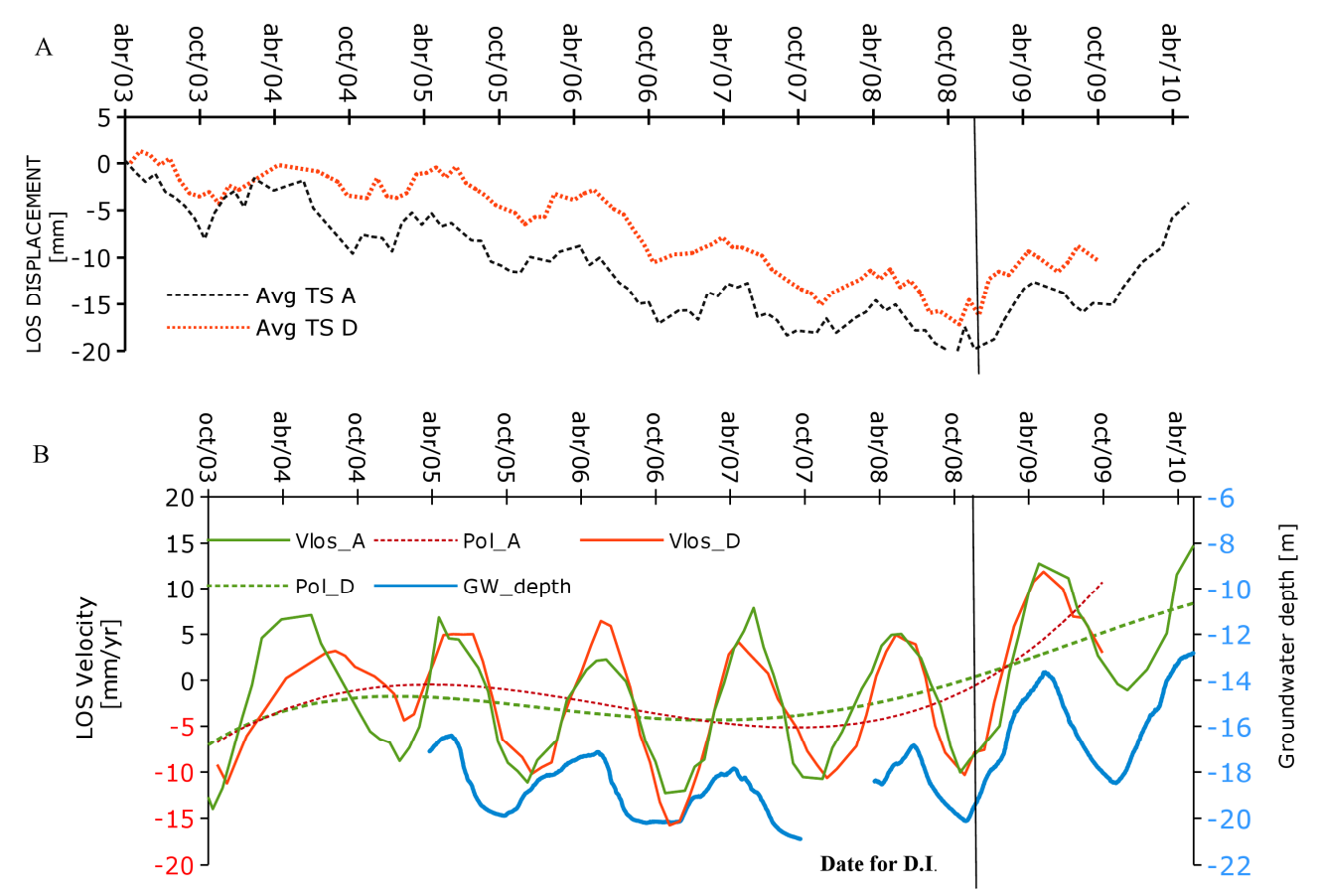

[Figure 10. A) Spatially averaged time series for ascending and descending geometry; B) LOS velocity time series for Pontecurone, using 6-month long averaging window, and 1 year interpolation windows. Results are shown for both ascending and descending RADARSAT-1 datasets, and compared with ground water levels (source: Regione Piemonte - Settore Acque).]

\subsection{Landslide, case history of Crociglia}

Crociglia landslide is a typical earth slide-earth flow that affects the weathered clay shale units widely outcropping in the NW Apennines. Borehole investigations suggested that the sliding surface is located at depths between $5 \mathrm{~m}$ and 15 $\mathrm{m}$ from the ground level, and recent field surveys evidenced presence of damage in residential buildings.

The analysis of RADARSAT-1 SqueeSAR ${ }^{\mathrm{TM}} \mathrm{V}_{\mathrm{LOS}}$ in ascending and descending mode shows an active sector within the urban settlement (Figure $11 \mathrm{~A}$ ). The landslide affects a west-facing, gentle slope $\left(10^{\circ}\right)$, and the main direction of the movement is horizontal, along the $\mathrm{E}-\mathrm{W}$ direction, as confirmed by negative $\mathrm{V}_{\mathrm{LOS}}$ in the descending dataset (i.e. -7 to -10 $\mathrm{mm} / \mathrm{yr}$ ), and positive $\mathrm{V}_{\mathrm{LOS}}$ in the ascending (i.e. +4 to $+6 \mathrm{~mm} / \mathrm{yr}$ ) dataset.

PS-Time automated classification of TS shows predominance of bi-linear, and linear behaviours only for a smaller portion of the TS, in both the ascending and the descending datasets (Figure $11 \mathrm{~B}$ ). Bi-linear points extend to the south of the landslide boundaries, suggesting that instability involves a wider area and incorporates the southern sector of the village. The date recording the change in the TS trend is autumn 2008. As for Pontecurone, the BICW index shows values higher than 1.2 , indicating strong bi-linearity.

The computation of DI1 was performed for 160 SqueeSAR ${ }^{\mathrm{TM}} \mathrm{TS}$ in descending, and $230 \mathrm{TS}$ in ascending mode, by using the $t_{b}$ of November 2008 for both the datasets. The DI1 maps (Figure $11 \mathrm{C}$ ) confirm spatially the extension of the deviations already evidenced by PS-Time, and DI1 values as high as 1.5 to 3.0 are observed, mostly within the mapped landslide boundaries, and part to the south, with DI1 peak of 3.4 in the descending dataset for a point just outside the landslide boundary.

The mobile DI approach shows that the TS of PS and DS within the landslide boundaries recorded similar deformation behaviour from the main scarp to the toe, thereby resulting in similar DI1 vs. $t_{b}$ curves. Figure 12 shows the example of PS A75VJ from the descending dataset (which best depicts the occurred deformation due to the aspect of the slope), located in the lower part of the landslide. The TS is dominated by LOS motion away from the satellite (Figure 12 B), 
with $-7.46 \mathrm{~mm} / \mathrm{yr} \mathrm{V}_{\mathrm{LOS}}$ and 0.97 coherence. Visual inspection of the TS highlights trend change only in the course of 2009 , in correspondence with the last SAR acquisitions. Using a priori $t_{b}$ on 30/11/2008 the DI takes on the value of 2.5 (Figure 12A), whereas the mobile DI provides a clearer picture (Figure 12C), by showing a DI1 increase during 2008 and the peak of 4.5 on 14/05/2009. The mobile DI calculation allows us to correct the interpretation and to detect objectively the trend change in 2009 that was already noted by visual inspection. The a priori $t_{b}$ of 30/11/2008 therefore cannot be considered the ideal date to break the TS, though still critical, as the trend deviation was already in place. The features observed in the TS of PS A75VJ are also found for the neighbouring PS and DS, thus indicating similar deformation behaviour for all the points within the landslide boundaries.

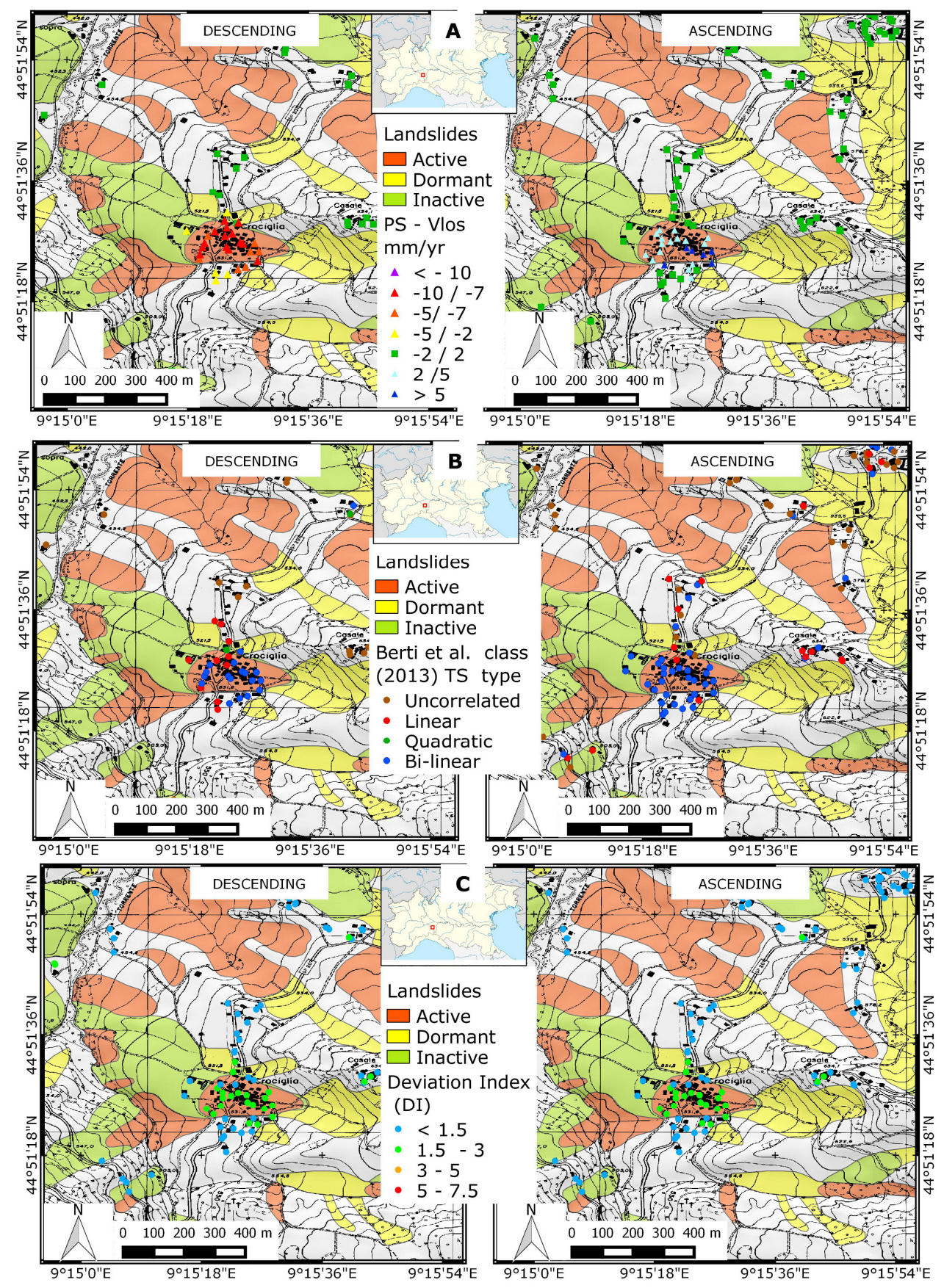

[Figure 11: RADARSAT-1 SqueeSAR ${ }^{\mathrm{TM}}$ time series for Crociglia A) LOS velocities based on (left) descending and (right) ascending mode data processed with SqueeSAR ${ }^{\mathrm{TM}}$ by TRE S.r.l.; B) Automated classification of RADARSAT-1 SqueeSAR ${ }^{\mathrm{TM}}$ time series in (left) descending and (right) ascending mode, based on PS-Time classification tool by BERTI et al. (2013).; C) Semi-automated classification (left) descending and (right) ascending mode, based on the Deviation Index (DI) approach by Cigna et al. (2012).] 


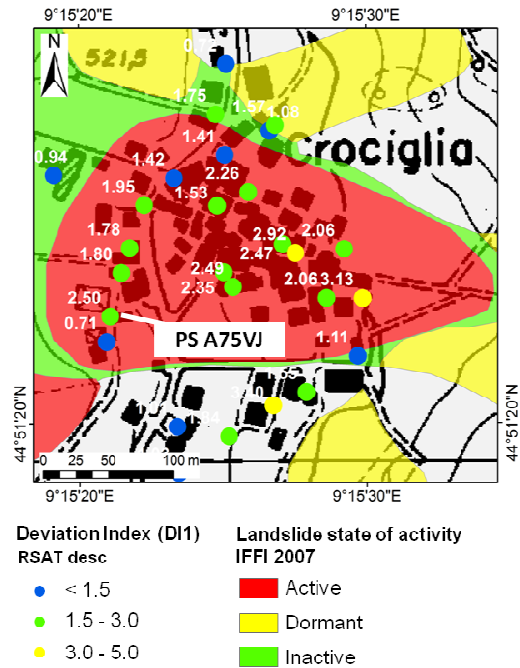

A
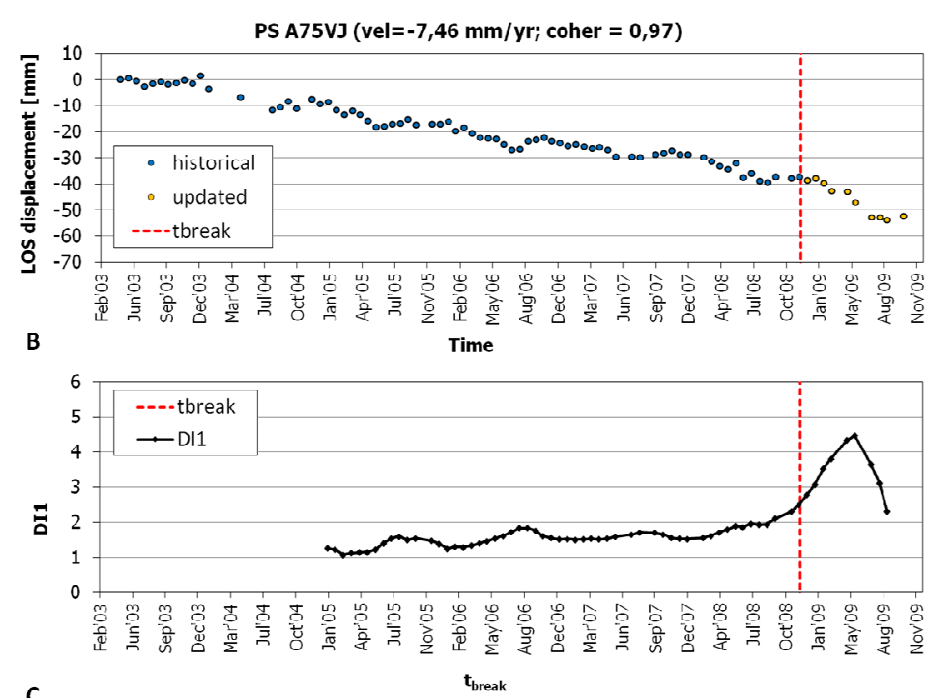

[Figure 12: A) Semi-automated classification of RADARSAT-1 SqueeSAR ${ }^{\mathrm{TM}}$ descending time series based on DI1 over Crociglia landslide (cf. Figure 11A), superimposed on landslide inventory (IFFI 2007) and topographic map sheet Regione Lombardia B9C1 scale 1:10'000; B) Time series and C) graph of DI1 vs. $t_{b}$ for the PS A75VJ. Red dashed line marks the a priori $t_{b}$ in November 2008.]

The analysis of the TS velocity was based on averages of $\sim 20$ ascending and $\sim 20$ descending TS of points within the landslide boundaries and allowed identification of two main types of trends. The first depicts a long-term behaviour and confirms the evidences from the DI computation and PS-Time automated classification (Figure $13 \mathrm{~A}$ ). The period between 2003 and 2008 shows $\mathrm{V}_{\mathrm{LOS}}$ of $-7 \mathrm{~mm} / \mathrm{yr}$ in the descending mode and $+4 \mathrm{~mm} / \mathrm{yr}$ in ascending mode. The velocity TS based on 6 months-long intervals shows seasonal variations for both acquisition geometries. Observed acceleration of the movements in winter-spring is followed by deceleration in summer/early autumn (Figure $13 \mathrm{~B}$ ). We also computed the E-W and vertical component of the velocity (Figure 13C). The projection of the 6-month $\mathrm{V}_{\mathrm{LOS}}$ to the steepest slope direction for both geometries shows equivalent results. Average velocity during the winter is $-20 \mathrm{~mm} / \mathrm{yr}$, whereas velocity during the summer ranges between -7 and $-4 \mathrm{~mm} / \mathrm{yr}$. The agreement between ascending and descending datasets, also confirmed by analysis of ERS data, allows us to consider this result reliable also without comparison with other monitoring data. The physical explanation of the observed seasonal trend is most likely related to seasonal variations in saturation level of the soil, controlled by rainfall, evapo-transpiration and snow melting. Longterm variations are thought to be related to rainfall, as the period between November 2008 and May 2010 was characterised by two rainy winter-spring periods. The main event occurred in April 2009, just after the $t_{b}$ that was identified by both PS-Time and the DI approach, and the landslide motions mainly occurred in the areas nearby. 


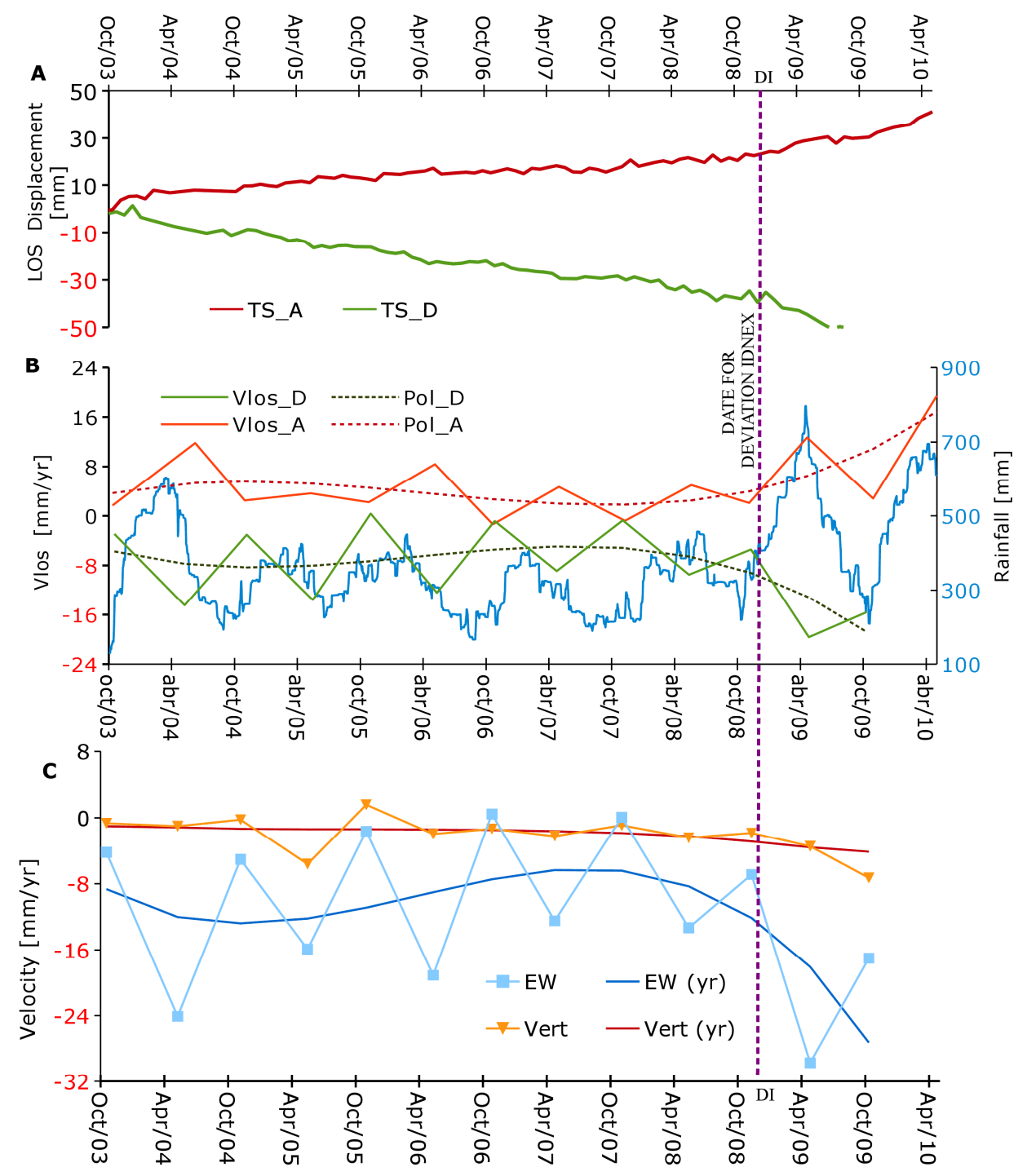

[Figure 13: A) Spatially averaged SqueeSAR ${ }^{\mathrm{TM}}$ time series for ascending and descending geometry of RADARSAT-1 datasets; B) LOS velocity time series for Crociglia, using 6 months averaging window, and 1 year interpolation windows. Results are shown for both ascending and descending RADARSAT-1 datasets, and compared with rainfalls (source: Arpa Lombardia). C) resolved E-W and vertical components of the velocity by combing ascending and descending RADARSAT-1 datasets.]

\section{Conclusions}

Deformation Time Series (TS) generated through advanced DInSAR techniques provide valuable information on the temporal evolution of geological processes as landslides and subsidence phenomena.

In this work we proposed and validated a methodology for the analysis of DInSAR TS, aimed at improving the understanding of the kinematical behaviour of geohazard processes and enabling also non-expert users to handle DInSAR deformation time series.

The proposed methodology consists of three main steps:

$>$ Pre-processing (see section 1): computation of the SAR Dataset Quality Index (SDQI) aimed at evaluating the quality of datasets prior to/in preparation to the trend analysis. Its assessment is based on five indexes associated to the 
characteristics of the available SAR datasets. SDQI was computed for several DInSAR datasets acquired by different SAR sensors and processed with advanced DInSAR techniques, i.e., PSInSAR ${ }^{\mathrm{TM}}$, SqueeSAR ${ }^{\mathrm{TM}}$, SBAS and SPN. The purposed SDQI can be applied to any other DInSAR techniques not tested in this work and it is an open instrument that can be discussed and improved by the community. The comparative tests showed that the optimal time-series should have the following features: a temporal span of 5-8 years, an almost complete series of images without long temporal gap (temporal baseline $<180$ days for L-band, $<90$ days for C-band; $<45$ days for X-band) and a good spatial baseline $(<1000 \mathrm{~m},<300 \mathrm{~m} ;<200 \mathrm{~m}$ respectively for $\mathrm{L}, \mathrm{C}$ and $\mathrm{X}$ band). The spatial resolution of sensor and the wavelength are also important, and SDQI approach also accounts for them.

$>$ Post-processing (see section 2):

application of four approaches aimed at mitigating some of the errors and noise that can affect DInSAR TS and improving their quality. These approaches are based on empirical-stochastic observations and address the removal of regional trends and anomalous motion values, the correction of possible phase unwrapping errors and the noise reduction trough spatial averaging. However, such methods for TS quality improvement need strong control interaction and input by the DInSAR users and cannot be used with full automation. In particular, for the phase unwrapping error correction it is important to check the geomorphological reliability with ground truth data to avoid false positives. Application of these approaches showed good results for the case histories in our areas of interest.

$>$ Detection and analysis of TS trends (see section 3): three different methodologies for DInSAR TS trend analysis were compared with respect to a common dataset characterized by a very high quality (SDQI=0.82) and when necessary, after quality improvement (as proposed in this work). These methodologies work on different aspects of the TS: (i) PS-Time automated classification is suitable when the deformation behaviour is unknown, and is able to suggest trend typology and other useful parameters (e.g., $t_{b}$, bi-linearity and seasonality indices); (ii) Deviation Index or DI, improved with the mobile DI, is suitable to detect the geological processes when TS show trend changes in relation to specific events (e.g. sudden collapse, heavy rainfall, tectonic motion); and (iii) the TS of velocity allows extraction of relevant temporal features (e.g., seasonality) at the local scale. The three methodologies were tested on two areas in Italy affected by urban subsidence and landslide processes, and showed agreement in picturing the motion behaviour of the investigated phenomena. In Pontecurone, the TS analysis allowed discovering of both seasonal and long-term ground oscillations, likely related to water level variations in the aquifers. In Crociglia, longterm and seasonal trend were detected, showing a correlation of landslide motions with rainfall records over 3-6 month long intervals.

The obtained results prove that the proposed methodology allows maximizing the information embedded in the DInSAR TS and encourage its implementation by end-users interested in improving the understanding of the deformation behaviour of geological processes.

\section{Acknowledgements}

The SAR data for Piemonte and Liguria regions in NW Italy were obtained through the project "Risk Nat" with Regione Liguria and ARPA Piemonte. The data over Oltrepò Pavese were derived from collaboration with Regione Lombardia. Both these data were processed by Tele-Rilevamento Europa - T.R.E. s.r.l. -. Datasets over Valle de Tena were derived from the SUDOE project in collaboration with IGME (Instituto Geologico Y Minero de España), Madrid, Spain, and processed by Altamira Information. SAR datasets over Umbria region, central Italy, were processed in the framework of the EC FP7 DORIS project (contract n. 242212). SAR datasets over Daunia Apennines, Southern Italy, were processed in the framework of contract with Italian Department of Civil Protection (contract n. 622). 


\section{References}

Arnaud, A., Adam, N., Hanssen, R., Inglada, J., Duro, J., Closa, J. and Eineder, M. (2003), ASAR ERS interferometric phase continuity. Geoscience and Remote Sensing Symposium, 2003. IGARSS '03. Proceedings. 2003 IEEE International, 2, pp.1133-1135, 21-25 July 2003.

Berardino, P., Fornaro, G., LANARI, R. AND SANSOSTI, E. (2002), A new algorithm for surface deformation monitoring based on small baseline differential interferograms. Geoscience and Remote Sensing, IEEE Transactions, 40, no.11, pp.2375-2383.

Berti, M., Corsini, A., Franceschini, S., And IAnnacone, J. P. (2013), Automated classification of Persistent Scatterers Interferometry time series, Nat. Hazards Earth Syst. Sci., 13, 1945-1958, doi:10.5194/nhess-13-1945-2013.

Bianchini, S., Cigna, F., Righini, G., Proietti, C., AND CASAgli, N. (2012), Landslide hotspot mapping by means of persistent scatterer interferometry. Environmental Earth Sciences, 67, pp 1155-1172.

Blanco-Sanchez, P., Mallorquí, J.J., Duque, S. And Monells, D. (2008), The Coherent Pixels Technique CPT): An Advanced DInSAR Technique for Nonlinear Deformation Monitoring, Pure Appl. Geophys., 165, pp. 1167-1194.

Bonano, M., MANunta, M., MARSElla, M., AND LANARI, R. (2012). Long-term ERS/ENVISAT deformation timeseries generation at full spatial resolution via the extended SBAS technique. International Journal of Remote Sensing, 33(15), 4756-4783.

Bovenga, F., Wasowski, J., NitTi, D. O., Nutricato, R., \& Chiaradia, M. T. (2012). Using COSMO/SkyMed X-band and ENVISAT C-band SAR interferometry for landslides analysis. Remote Sensing of Environment, 119, 272-285.

Calò, F., Ardizzone, F., Castaldo, R., Lollino, P., Tizzani, P., Guzzetti, F., Lanari, R., Angeli M.-G., Pontoni, F. AND MANUNTA, M. (2014). Enhanced landslide investigations through advanced DInSAR techniques: The Ivancich case study, Assisi, Italy. Remote Sensing of Environment, 142, 69-82.

CASU, F., MANZO, M., \& LANARI, R. (2006). A quantitative assessment of the SBAS algorithm performance for surface deformation retrieval from DInSAR data. Remote Sensing of Environment, 102(3-4), 195-210. DOI:10.1016/J.RSE.2006.01.023

Chen, F., Lin, H., Yeung, K., And Cheng, S. (2010), Detection of slope instability in Hong Kong based on multibaseline differential SAR interferometry using ALOS PALSAR data, GIScience Remote Sens., 47, $208-220$.

Cigna, F., TAPETE, D., AND CASAgLI, N., (2012): Semi-automated extraction of Deviation Indexes (DI) from satellite Persistent Scatterers time series: tests on sedimentary volcanism and tectonically-induced motions, Nonlin. Processes Geophys., 19, 643-655.

COLESANTI, C. AND WASOWSKY, J. (2006) Investigating landslides with space-borne Synthetic Aperture Radar (SAR) interferometry, Eng Geol., 88, 173-199.

Crosetto, M And Cuevas, M. (2011). Enabling Access to Geological Information in Support of GME. EUROPEAN COMMISSION Seventh Framework Programme D3.6 PSI Validation Version 1 17th November 2011.

Crosetto, M., Monserrat, O., IGlesias, R., AND CRIPPA, B. (2010). Persistent Scatterer Interferometry: Potential, limits and initial $C$ - and $X$-band comparison. Photogrammetric Engineering and Remote Sensing, 76 (9), $1061-1069$.

Devanthéry, N., Crosetto, M., Monserrat, O., Cuevas-GonzÁlez, M., \& CripPA, B. (2014). An Approach to Persistent Scatterer Interferometry. REMOTE SENSING, 6(7), 6662-6679.

Farina, P., Colombo, D., Fumagalli, A., Marks, F. And Moretti S. (2006) Permanent Scatterers for landslide investigations: outcomes from the ESA-SLAM project Engineering Geology, 88 (3-4), pp. 200-217.

Ferretti, A., Prati, C. AND RoccA, F., (2001) Permanent Scatterers in SAR interferometry. Geoscience and Remote Sensing, IEEE Transactions, 39(1).pp 8-20.

Ferretti, A., Prati, C., RocCA, F., \& WAsowski, J. (2006). Satellite interferometry for monitoring ground deformations in the urban environment. In Proc. 10th IAEG Congress, Nottingham, UK (CD-ROM).

Ferretti, A., Fumagalli, A., Novali, F., Prati, C., RocCA, F. And Rucci, A., (2011) A New Algorithm for Processing Interferometric Data-Stacks: SqueeSAR. IEEE T Geo-science and Remote Sensing, IEEE Transactions, 49 (9), pp.3460-3470.

FRANCESCHITTI, G., AND LANARI, R. (1999) Synthetic aperture radar processing. CRC press.

GONZÁlEZ, P. J., \& FERNÁNDEZ, J. (2011). Error estimation in multitemporal InSAR deformation time series, with application to Lanzarote, Canary Islands. Journal Of Geophysical Research: solid earth (1978-2012), 116(b10).

HANSSEN, R. (2001), Radar Interferometry: Data Interpretation and ErrorAnalysis, 308 pp., Kluwer Acad., Dordrecht, Netherlands 
Herrera, G., Gutiérrez, F., García-Davalillo, J. C., Guerrero, J., Notti, D., Galve, J. P., \& Cooksley, G. (2013). Multi-sensor advanced DInSAR monitoring of very slow landslides: the Tena valley case study (central Spanish Pyrenees). Remote Sensing of Environment, 128, 31-43.

HOOPER, A. (2008). A multi-temporal Insar method incorporating both persistent scatterer and small baseline approaches. Geophysical Research Letters, 35(16), L16302. HTTP: //DX.DOI.ORG/10.1029/2008GL034654.

Marinkovic, P. S., VAn LeiJen, F., KetelaAR, G., \& HANSSEN, R. F. (2005). Recursive data processing and data volume minimization for PS-InSAR. In INTERNATIONAL GEOSCIENCE AND REMOTE SENSING SYMPOSIUM (Vol. 4, p. 2697).

Meisina, C., Zucca, F., Notti, D., Colombo, A., Cucchi, A., Savio, G., Giannico, C. And Bianchi M. (2008), Geological interpretation of PSInSAR data at regional scale. Sensors 8, 7469-7492.

Metternicht, G., Hurni, L., And Gogu, R. (2005), Remote sensing of landslides: An analysis of the potential contribution to geo-spatial systems for hazard assessment in mountainous environments. Remote Sensing of Environment 98, $284-303$.

MILONE, G. AND SCEPI, G. (2011) A clustering approach for studying ground deformation trends in Campania Region through the use of PS-InSAR time series analysis, J. Appl. Sci. Res., 11, 610-620.

Mora, O., MALlorqui, J. J., AND BroquetAS, A. 2003. Linear and nonlinear terrain deformation maps from a reduced set of interferometric SAR images. IEEE Transactions on Geoscience and Remote Sensing, 41(10), $2243-2253$. HTTP://DX.DOI.ORG/10.1109/TGRS.2003.814657.

RASPINI, F., LOUPASAKIS, C., ROZOS, D., ADAM, N. AND MORETTI, S., (2014) - Ground subsidence phenomena in the Delta municipality region (Northern Greece): Geotechnical modelling and validation with Persistent Scatterer Interferometry. International Journal of Applied Earth Observation and Geoinformation, Vol. 28, pp 78-89

RocCA, F. (2007). Modeling interferogram stacks. Geoscience and Remote Sensing, IEEE Transactions on, 45(10), 3289-3299.

Sousa, J. J., Ruiz, A. M., Hanssen, R. F., Bastos, L., Gil, A. J., Galindo-Zaldívar, J., \& SAnz De Galdeano, C. (2010). PS-InSAR processing methodologies in the detection of field surface deformation-Study of the Granada basin (Central Betic Cordilleras, southern Spain). Journal of Geodynamics, 49(3), 181-189.

Sowter, A., Bateson, L., Strange, P., Ambrose, K., AND FifiK SyafiUdin M. (2013) DInSAR estimation of land motion using intermittent coherence with application to the South Derbyshire and Leicestershire coalfields. Remote Sensing Letters 4(10): 979-987.

Teatini, P., Tosi, L., Strozzi, T., Carbognin, L., Cecconi, G., Rosselli, R., \& LiBardo, S. (2012). Resolving land subsidence within the Venice lagoon by persistent scatterer SAR interferometry. Physics and Chemistry of the Earth, Parts A/B/C, 40, 72-79.

TAPETE, D., AND CASAGLI, N. (2013), Testing Computational Methods to Identify Deformation Trends in RADARSAT Persistent Scatterers Time Series for Structural Assessment of Archaeological Heritage. In B. Murgante et al., (eds.), Computational Science and Its Applications - ICCSA 2013 (pp. 693-707): Springer Berlin Heidelberg.

TOMAS, R., Herrera. G., LOPEZ-SANCHEZ, J.M., ET AL.(2010). Study of the land subsidence in the Orihuela city (SE Spain) using PSI data: distribution, evolution and correlation with conditioning and triggering factors. Engineering Geology, 115, 105-121. 